\title{
Indicadores científicos: evaluaciones negativas proposiciones positivas
}

\author{
Pied Ad DÉctor GutiérRez \\ Wagner 140 . La Paloma. 58290, Morelia, \\ Michoacán, México
}

\begin{abstract}
RESUMEN
La investigación científica es una actividad social, por ese motivo la evaluación de su productividad y eficiencia llega a ser imperativa.

El medio más común elegido por losinvestigadores para difundir sus conocimientos son las publicaciones periódicas primarias. La distribución, dispersión, impacto, y difusión de los artículos publicados en estas revistas científicas se pueden deducir a partir del análisis y evaluación de los indicadores cuantitativos que están basados en el análisis estadístico de las variables que caracterizan y definen el comportamiento en cada una de las respectivas ramas del saber. Los resultados obtenidos en este tipo de estudios ofrecen la información requerida tanto para la toma de decisiones en materia de política informativa como en materia de política científica.

D e acuerdo con lo anterior este trabajo propone indicadores científicos, resultado de la información obtenida a partir de los currículos de los investigadores de la UNA M en el área científica, con el propósito de aportar resultados objetivos sin los sesgos que usualmente presentan las bases de datos comerciales.
\end{abstract}

\section{SCIENTIFIC INDICATORS: NEGATIVE EVALUATIONS POSITIVE PROPOSITIONS} Piedad DéCt O R-GutiérReZ

\section{A BSTRACT}

Scientific research is a social activity. For this reason, the evaluation of its productivity and effectiveness have become imperative.

The most common media chosen by researchers to disseminate their knowledge is primary journals. The distribution, dispersion, impact, and diffusion of the articles published in these journals can be deduced through the analysis and evaluation of the quantitative indicators based on the statistical analysis of the variables which characterize and define the behavior for each of the respective branches of knowledge. The results obtained in this type of work provide the data needed for making decisions regarding information and scientific policies. A s previously stated in this paper, scientific indicators are suggested in the information being obtained from the UNAM researchers' curricula vitarum in the scientific area. The stated goal being to give objective results without the typical bases usually present in commercial databases.
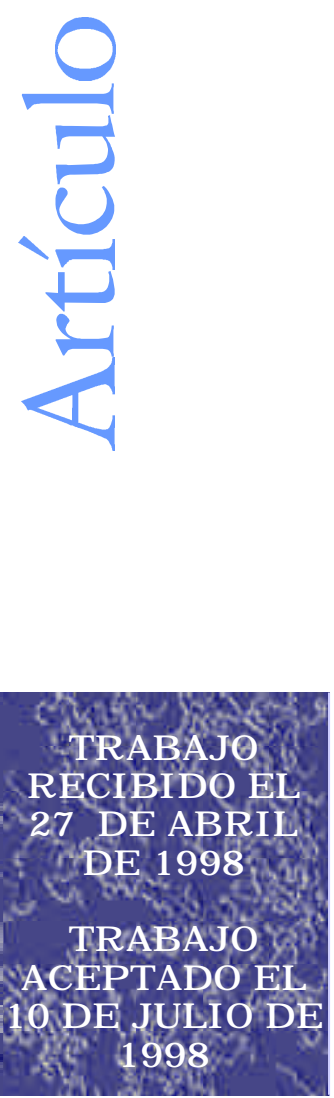


\section{OBJETIV O}

La identificación de indicadores que coadyuven a una medición más objetiva de la producción científica mexicana.

\section{Á MBIT 0}

Centros e institutos pertenecientes a la Coordinación de la Investigación Científica de la Universidad Nacional Autónoma de México.

C entros de: Ciencias de la atmósfera, E cología, Instrumentos, Investigación sobre Fijación de Nitrógeno y N eurobiología.

Institutos de: A stronomía, Biología, Biotecnología, Ciencias del Mar y Limnología, Ciencias Nucleares, G eografía, G eología, G eofísica, Física, Fisiología C elular, Ingeniería, Investigaciones Biomédicas, Investigaciones en Matemáticas A plicadas y Sistemas, Investigaciones en Materiales, Matemáticas y Q uímica.

\section{PARTICIPANTES}

854 académicos que cultivan la actividad científica y tienen el nombramiento de "Investigadores" de acuerdo con su contrato laboral.

\section{Procedencia de LOS DATOS}

Para la extracción de los datos, fue necesario acudir a los currículos de los investigadores, ya que conforman una fuente de información validada, objetivay confiable. Estos datos fueron revisados, analizados y capturados, en 3 bancos de información. El primero con los datos personales de 1384 académicos, el segundo contiene aproximadamente 40000 referencias de documentos publicados por esos académicos y el tercero está conformado por 140000 referencias relativas a los trabajo s citantesy trabajos citados de la producción de esta comunidad; se utilizó como apoyo el SaienœCitation Index(SCI). Para este trabajo el número de documentos publicados que se analizó fue de 39525 y de citas un total de 139919.

\section{PERIODO}

Comprende la totalidad de los trabajos publicados por los investigadores, incluidos en su curriculum, por lo tanto es histórico. 
66 Investigación Bibliotecológica v. 12 N o. 25 julio/ diciembre de 1998

\section{INTRODUCCIÓN}

T ainversión en ciencia y tecnología del Producto Interno Bruto (PIB) en paí$\perp$ ses como Estados Unidos, A lemania, Japón y Gran Bretaña es del 2\%. En Corea, Taiwan, Singapur y Malasia es de 1.6\% y en México de 0.35\% (CO NACyT, 1995).

El bajo porcentaje de inversión que nuestro país aplica a este sector posiblemente tiene como origen el que la actividad científica profesional en nuestro país es joven, ya que por ejemplo en la UN A M sólo 3 institutos - aunque con antecedentes- se fundaron en 1929, dos en 1938, cuatro en los años cuarenta, tres en los setenta y cuatro en los ochenta. O tra razón para explicar los bajos recursos asignados a la actividad científica es que ésta ha dado pocos frutos visibles para la sociedad, por consiguiente el gobierno no tiene la demanda de los mexicanos de que se le impulse.

Si se analiza la inversión que el sector privado destina al desarrollo en Ciencia y T ecnología es posible observar que ésta varía dependiendo del país, por ejemplo, en economías como la de Corea -según datos proporcionados por el CO NA CyT - el porcentaje del total es de un 90\%, mientras que en México esta inversión sólo alcanza un 15\% o si se quiere hacer la comparación con un país latinoamericano, encontramos que Brasil destina un 50\% del total de la inversión privada al desarrollo de su investigación.

Con los datos anteriores se puede determinar que la ausencia de un plan estratégico establecido entre el gobierno y la comunidad científica en el que se definan los proyectos nacionales seguirá manteniendo a la actividad científica disminuida frente a otras muchas "prioridades nacionales."

Como un fin primordial de adecuar convenientemente la asignación de los escasos recursos que México destina al desarrollo de la ciencia surge la necesidad, de parte de quienes toman las decisiones, de evaluar el rendimiento de la actividad científica, así como de los canales formales que ésta utiliza para su difusión, mediante el análisis de las tendencias que caracterizan y definen su comportamiento, así como el efecto que éstas provocan en la sociedad.

Para la evaluación del rendimiento de la actividad científica son utilizados dos tipos de indicadores: cualitativos y cuantitativos. D e los primeros se puede decir que son los pares quienes los determinan, ya sea como individuos, o por medio de comités o consejos, y respecto a los segundos o sea los indicadores cuantitativos son utilizados desde la segunda década de este siglo, sobre todo por quienes están estrechamente relacionados con la información científica.

Los indicadores cuantitativos están basados en el análisis estadístico de las variables que caracterizan el comportamiento de la producción científica y son utilizados con el propósito de evaluar los procesos de generación, propagación, uso e impacto de la literatura científica, ya que ésta establece el canal idóneo de 
transmisión de los resultados científicos en cualquier país, por lo que el análisis de esta literatura científica constituye un legítimo indicador.

Cada día to ma mayo r importancia la evaluación de los resultados científicos que alcanzan difusión a través de las fuentes impresas de información, en particular las revistas científicas, por constituir éstas el medio o canal más común elegido para difundir los conocimientos científicos. No se trata solamente de contar artículos científicos, como dato único, sino de que de su análisis y evaluación se puedan deducir, entre otros aspectos, la distribución, dispersión, impacto y difusión que caracterizan y definen el comportamiento de la comunicación científica en cada rama del saber.

Los resultados obtenidos en este tipo de estudio ofrecen información, en una primera etapa, de tipo descriptivo - su valor está en la riqueza de información que contienen- más adelante con la aplicación de estadística inferencial será posible hacer predicciones tanto para la toma de decisiones en materia de política informativa como para la toma de decisiones en política científica.

Conviene tomar en cuenta también otros aspectos relativos a este tipo de estudios, por ejemplo, uno de ellos es la falta de continuidad y de seguimiento. Cuando se trata de hacer una evaluación global de la producción científica nacional, manifestada a través de los llamados canales formales o publicaciones impresas de la comunicación científica, es una práctica común solicitar estudios por única vez, estos estudios por lo regular son proposiciones que dan respuesta a una necesidad de información inmediata, pero que no constituyen una práctica sistemática que deba ser considerada en la toma de decisiones sobre política científica y de información.

O tro aspecto es el sesgo que presentan los resultados cuando la información se obtiene nada más de la consulta a bases de datos comerciales. Es decir, si a través de un estudio se deseara comparar la producción nacional de modo interno, por ejemplo entre instituciones, dependencias u otras jerarquías, o quizá se requiriera comparar la producción de México con otros países, necesariamente se tendría que recurrir a fuentes internacionales como lo índices y resúmenes bibliográficos- Index and A bstracts- los cuales registran las publicaciones científicas divididas, entre otras, en ramas del conocimiento, países, e instituciones. A unque los resultados que ofrecen estas bases de datos siempre se consideran un apoyo para conocer el estado del arte de cualquiera de las variables antes mencionadas, es conveniente tomar en cuenta algunas limitaciones, éstas pueden ser: la exclusión de publicaciones de países en desarrollo; la tendencia a incluir publicaciones concentradas en las grandes revistas internacionales; la determinación de incluir preferentemente literatura en inglés; la desigualdad de condiciones, ya que aunque las revistas registradas tienen representatividad en cada campo de la ciencia, ésta se presenta con diferente peso y al final, el número total de títulos de revistas analizadas en el mundo se calcula que es de 53000 revistas científicas, de las 
cuales sólo 3300 revistas arbitradas son cubiertas por el SaienceCitation Index (Sen, B., Karanjai, A . y Munski, U. 1989).

D e ahí puede concluirse que los resultados siempre presentaran el sesgo antes mencionado. Por esto s motivos se hace cada vez más necesario considerar la evaluación de los resultados científicos de nuestros países a través de fuentes de información propias, es decir, desarrolladas por los mismos países, que permitan una mayor veracidad en los resultados obtenidos.

Si tomamos como referencia los planteamientos anterioresy si conocemos de antemano la conveniencia de no depender exclusivamente de las bases de datos externas, se puede considerar como una necesidad el establecimiento de fuentes formadas con información validada, objetivay confiable propias de cada país. Al consultar estas fuentes los resultados obtenidos estarán ajustados a la comunidad analizada.

El propósito de este estudio es determinar las tendencias, por medio de un análisis descriptivo, que se manifiestan en la producción científica de los investigadores del Subsistema de la Investigación Científica (SIC) de la Universidad Nacional A utónoma de México (UNA M), para lo que se tiene como fuente original los currículos de los propios investigadores. La UNA M tiene en nuestro país un gran peso académico, ya que es la institución mexicana en la que se cultiva un mayor número de disciplinas, así como la que por mucho produce el mayor porcentaje de la producción bibliográfica nacional, por lo tanto los criterios aplicados a este grupo pueden generalizarse para la evaluación de la producción científica mexicana.

Al conocer el comportamiento de las variables que caracterizan y definen a la producción científica se aportan nuevos elementos que puedan ser incorporados en la toma de decisiones sobre política científica y de información.

\section{EL USO DE INDICADORES EN LA EVALUACIÓN DE LA PRODUCCIÓN CIENTÍFICA}

\section{La ciencia y la sociedad}

La ciencia es indispensable en las sociedades modernas, ya que forma parte de sus estructuras socioeconómicas, culturales y políticas. No es una esfera independiente de la sociedad, sino una esfera de la actividad investigadora dirigida a o bservary a estudiar el mundo real que nos rodea, y que al unirse con la tecnología crea bienes de consumo que elevan la calidad de vida de la población, produciendo información y resolviendo problemas de incertidumbre de conocimiento del ho mbre ante la naturaleza y los fenómenos naturales, con lo cual va creando el acervo que permite a la sociedad desarrollarse. 
Indicadores científicos: evaluaciones negativas proposiciones positivas 69

Al respecto Sir Isaac N ewton dijo:

"If I havesen further it is only because I stood on the shoulders of giants" (Si puedo ver más allá essólo porquemeparéen los hombros delos gigantes.)

La ciencia influye en las actividades humanas ya sean individuales, de grupos, de instituciones y hasta de naciones. Por lo tanto la evolución de cualquier individuo o de las sociedades, no importa el tamaño de éstas, depende del desarrollo científico y tecnológico. Ferrater (1975) define a la ciencia como el conocimiento que mediante lenguajes rigurosos y apropiados aspira a formular -en lo posible, con auxilio del lenguaje matemático- leyes por medio de las cuales se rigen los fenómenos.

Aunque en una sociedad el número de individuos comprometidos con la ciencia, así como los recursos asignados a ésta, proporcionalmente son pequeños, sus efectos, directos o indirectos, son enormes (Moravcsick, M.J., 1989).

La sociedad debería soportar esta estructura y pagar por ello cada vez más, porque el resultado del trabajo científico es vital para la fuerza, la seguridad y el bienestar de todos.

Respecto a los países desarrollados se menciona que las expectativas de bienestar social están fijadas en la ciencia y la tecnología, hasta el punto en que se produce una fuerte competencia entre los países por la carrera de su desarrollo, considerándolo como una de las mayores aspiraciones de la humanidad (Sancho, R. 1990).

La ciencia tiene como característica su contemporaneidad, ya que en la actualidad vive entre el 80 y el 90 por ciento de los científicos que haya registrado la historia. O tra característica es el crecimiento exponencial. La ciencia crece al multiplicarse por una cantidad determinada en periodosiguales. D ependiendo de qué es lo que se vay a a medir y del indicador que se utilice, ya sea para individuos o para publicaciones, el tamaño tiende a duplicarse en un periodo de entre10 y 15 años (D e Solla Price, D ., 1963).

Como ya se mencionó, la ciencia forma parte de la sociedad, no es una esfera independiente. A sí como la ciencia es una esfera de la actividad investigadora, la actividad bibliológico-informativa es una esfera de la actividad económica, dirigida a satisfacer las necesidades de información de los usuarios.

\section{Sistema Ciencia, Investigación y Desarrollo}

D ada la importancia de la ciencia frente a la sociedad surge la necesidad de evaluar el rendimiento de la actividad científica y su impacto social, a fin de proporcionar de manera adecuada los recursos que aseguren su desarro llo y la máxima rentabilidad de las inversiones que asignan los países a este rubro, dentro de su presupuesto. 
70 Investigación Bibliotecológica V. 12 N o. 25 julio/ diciembre de 1998

Sin embargo, evaluar el rendimiento de la actividad científica no es tarea fácil, ya que el producto de la ciencia no es obvio ni tangible. Con un producto abstracto como el conocimiento y la comprensión del mundo que nos rodea, la evaluación no puede llevarse a cabo de una forma predeterminada ni automática.

Como la magia o la religión, la ciencia es un tipo de saber, una manera de ver el mundo, confiable hoy pero cuestionable mañana. Kuhn (1971) señala que la ciencia es dinámica, imperfecta y contradictoria, Chalmers (1982) agrega que además, es un saber que pretende ser útil, pero también racional, sistemático, objetivo, verificable y perfectible. Para Feyerabend (1981) la ciencia es un tipo de saber que intenta describir, explicar, o predecir, fenómenos de la realidad, pero que contiene un margen de error, a veces grande.

En su conferencia sobre ¿cómo evaluar la ciencia y a los científicos? presentada en Madrid en 1989, Michael Moravcsik señala que hay muchas razones por las cuales es importante evaluar a la ciencia y a los científicos, entre o tras, él menciona cuatro, y señala que:

- Los resultados son intangibles.

Hay pro cesos simples, en los servicios, que no requieren de una evaluación formal porque sus resultados se pueden percibir de modo preciso. El de un sistema de búsquedas de citas a trabajos publicados por un autor determinado se hace simplemente comprobando si el resultado curricular fue recibido por el investigador solicitante con rapidez y de manera oportuna. En cambio si se deseara evaluar el contenido de esos conocimientos resultaría imposible para alguien que no fuera especialista en el tema, y aun así esta evaluación sería difícil sin una unidad de medida, ya que el producto de la ciencia es el conocimiento y la comprensión del mundo que nos rodea. D ebido a que el proceso de evaluación en la ciencia no se lleva a cabo de manera automática es importante determinar evaluaciones que permitan comprobar su rendimiento a largo plazo.

* Tiene un gran impacto porque la ciencia incide en el desarrollo de la sociedad. Mario Jo sé Molina, premio N obel de Q uímica 1995, advirtió en 1974 la destrucción de la capa de ozono por efecto delos clorofluorometanos, y logró la reglamentación internacional para el control de la emisión de los contaminantes de la atmósfera y la utilización de tecnologías que no implican la liberación de clorofluorocarburos. También consiguió, mediante los resultados de sus investigaciones, que las empresas químicas fueran conscientes de los productos que causan un daño irreparable en el hombre y no solamente obtuvo eso, sino que además logró que estas mismas empresas sean ahora las promotoras de este tipo de investigación. Este ejemplo puede demostrarnos que cuando un resultado científico es verdadero, por pequeño que sea, su impacto puede trascender en el tiempo y en todo el universo de aplicaciones. Su productividad 
Indicadores científicos: evaluaciones negativas proposiciones positivas 71

es sesgada, esto es, está limitada a partir de un determinado núcleo de investigadores.

Price (1963) menciona que la proporción que se establece entre un grupo de investigadores y la cantidad de trabajos científicos que publican es la siguiente:

\begin{tabular}{|l|l|}
\hline \multicolumn{1}{|c|}{ investigadores } & \multicolumn{1}{c|}{ publican } \\
\hline 10000 & 1 trabajo \\
\hline 100 & 10 trabajos \\
\hline 1 & 100 trabajos \\
\hline
\end{tabular}

Por lo tanto el sesgo se da en un nivel concentrado en un núcleo de autores, por ese motivo G arfield opina que al asignar recursos hay que conocer, entre otros, el sesgo de alta productividad.

* ¿Es posible administrar la ciencia?

Si la ciencia no se administra, si no se miden su productividad y su impacto no tendremos con qué marcar pautas de política científica. La actividad científica debe ser evaluada y administrada.

En estos puntos Moravsick sintetiza la importancia que tiene la evaluación de la ciencia, por ser una esfera de la actividad investigadora, dirigida a satisfacer necesidades de consumo de la población, de conocimiento y de información.

\section{Fundamentación de uso de indicadores en la evaluación de la producción científica}

La evaluación de la actividad científica, por medio de indicadores como un elemento primordial dentro de cualquier programa de política científica, se considera hoy una práctica necesaria aunque no generalizada.

Estas evaluaciones facilitan la distribución de los limitados recursos económicos que cada país puede destinar al área de la investigación científica.

Es a partir de los años setenta que las autoridades responsables de la planificación científica demandaron con mayor énfasis estudios métricos de la información publicada. El fin era conocer si la planeación había producido el efecto o había logrado el propósito para el que estaba destinada, en pocas palabras, querían evaluar la eficacia de sus políticas y si esos sistemas científicos aportaban un análisis costo-beneficio.

Es así que organismos internacionales relacionados con la valoración del progreso científico publicaron sus aportaciones a esta demanda, entre ellos, la 
National Science Foundation (NSF) y la O rganización para la Cooperación y el Desarrollo Económico (O CDE).

La National Science Foundation publica el Saience Indicators Reports, además de otros trabajos elaborados por Francis Narin y sus coautores. Cuando este reporte se publicó tuvo repercusiones en varios sentidos, una de ellas, muy importante, fue el estímulo para publicar más estudios sobre bibliometría evaluativa, lo que motivó el desarrollo de este campo.

El SaienceIndicators Reportsfue publicado por primera vez en 1972. Su alcance fue análogo al del Social IndicatorsReports preparado y publicado por el gobierno de los Estados Unidos. Estos estudios métricos de la información y entre ellos los que analizan las publicaciones periódicas primarias, fueron calculados con fundamento nacional, con objeto de monitorear el estado, calidad y competitividad de los Estados Unidos en ciencia y tecnología.

Por su parte la O CDE, creada el 30 de septiembre de 1961, publica repertorios de indicadores de inversión en ciencia para sus 25 países miembro, deA mérica del N orte, de Europa $\mathrm{O}$ ccidental y del Pacífico. México ingresó en la O rganización el 18 de mayo de 1994. En la O CD E sereúnen los representantes de los go biernos para comparar y co ordinar sus políticas nacionales e internacionales en más de 25 campos concentrados en 9 direcciones, una de ellas es la de Ciencia y tecnología. En esta dirección los expertos sesionan apoyándose en los estudios analíticos realizados por la Secretaría de la O rganización. Estos estudios analizan diferentes aspectos de la política científica de un país, entre ellos la producción científica a partir de la obra publicada. Los análisis tienen una doble finalidad: en primer lugar, permitir que los países interesados puedan evaluar las medidas adoptadas con el fin de fortalecer el papel que desempeña la investigación científica en la realización de objetivos nacionales. En segundo lugar mostrar el contenido de las políticas científicas y tecnológicas y su función como instrumento de gobierno.

La expansión de los estudios de evaluación realizados por estas dos entidades, así como otros estudios posterio res desarrollados por diferentesinstancias, fue posible en gran medida debido a la facilidad de consultar la información a través de las bases de datos comerciales, que a partir de los años sesenta tuvieron un desarrollo sólido.

Los indicadores se pueden definir como:

* Una medida que provee información sobre los resultados de la actividad científica en una institución, país, o región del mundo ( Spinak, E. 1996).

* Los parámetros utilizados en el proceso de evaluación de cualquier actividad (Sancho, R. 1990).

* Una medida que proporciona información acerca dela naturaleza de un campo del conocimiento (D iodato, V. 1994). 
Indicadores científicos: evaluaciones negativas proposiciones positivas 73

Como ya se mencionó, los problemas relacionados con el estudio de las cantidades de documentos científicos y las magnitudes delos flujos de información fueron abordados en forma intensiva desde principio de los años setenta, aunque los primeros trabajos que incluían un conteo para estudiar diversos aspectos de las publicaciones se realizaron desde principios de este siglo.

Narin, F. (1976) afirma que "la iniciativa para analizar las revistas científicas vino de las bibliotecas".

Por décadas los bibliotecarios han utilizado las referencias para hacer estudios que les permitan optimar sus colecciones. Si bien sus datos son contables, el motivo es claramente evaluativo.

Cole, F. J. y Eales, N. B. (1917) publicaron el primer artículo que trataba de una manera incipiente sobre bibliografía comparada. Gross, P. y Gross, E. (1927) fueron los primeros en utilizar las citas para una evaluación. En un documento publicado en ese año tuvieron la idea de usar las referencias de una revista científica para identificar los títulos clave en una materia o disciplina. Por ese motivo este documento está considerado dentro de una estructura cronológica, como el primero de la literatura científica que estudia las revistas científicas. $\mathrm{El}$ artículo de $\mathrm{G}$ ross y $\mathrm{G}$ ross reflexionaba sobre la reconsideración en la adquisición de títulos para un servicio eficaz en la biblioteca de la Universidad de Pomona en $\mathrm{C}$ alifornia, ya que la principal preocupación de estos autores estaba centrada en los problemas que tenían que encarar sus propios estudiantes cuando entraban en competencia con estudiantes provenientes de grandes universidades que contaban con enormes bibliotecas centrales.

La situación enfrentada por la biblioteca de la Universidad de Pomona era difícil, ya que tanto el espacio como el presupuesto asignado eran limitados. A sí que decidieron encontrar una solución a su problema por medio de una selección de las revistas más importantes. Para llevar a cabo este ejercicio eligieron las revistas publicadas en el campo de la Q uímica. G ross y G ross decidieron hacer una lista compilando manualmente los títulos, pero se dieron cuenta de que esto tenía restricciones en cuanto a la subjetividad, y manifestaron que "a menudo los resultados pueden estar muy sesgados dependiendo de las necesidades, preferencias y rechazos del compilador." Entonces decidieron desarrollar una técnica más objetiva que analizara las referencias del volumen más reciente y completo -1926- con todas las referencias aparecidas en los artículos publicados en la revista Journal of theAmerican Chemical Society (JA C S). D espués tabularon, en intervalos de 5 años, las referencias a las revistas más citadas introduciendo así el concepto de jerarquización (ranking) de las revistas, por la frecuencia de las citas que recibían y la importancia de su distribución en el tiempo. Encontraron cuáles eran las revistas citadas con más frecuencia, e hicieron una diferenciación entre las publicadas en Estados Unidos y las publicadas en otros países e idiomas diferentes del inglés. También identificaron algunos otros parámetros que eran comunes en la literatura química internacional. 
74 Investigación Bibliotecológica v. 12 N o. 25 julio/ diciembre de 1998

\section{Significación de la producción científica de la U N A M y su repercusión en el entorno nacional}

La investigación que se lleva a cabo en la Universidad Nacional A utónoma de México (UNAM) es reconocida tanto en el entorno nacional como en el internacional. Para atender y solucionar los diversos problemas que enfrenta la sociedad mexicana, la UN A M forma cuadros altamente calificados, que pueden ser preparados por la misma universidad, o apoyados por medio de becas, para obtener en el extranjero niveles de posgrado, otorgados por instituciones de educación superior de gran prestigio.

En México el mayor número de personas con doctorados nacionales, es egresado de esta institución (UNA M , 1988). D e esta forma la UN A M prepara a sus académicos para conformar y desarrollar una comunidad científica de alto nivel, que participa y contribuye al avance del conocimiento en el mundo. Este alto nivel puede ser avalado con los numerosos reconocimientos que reciben sus miembros, interna y externamente.

\section{Gráfiø 1}

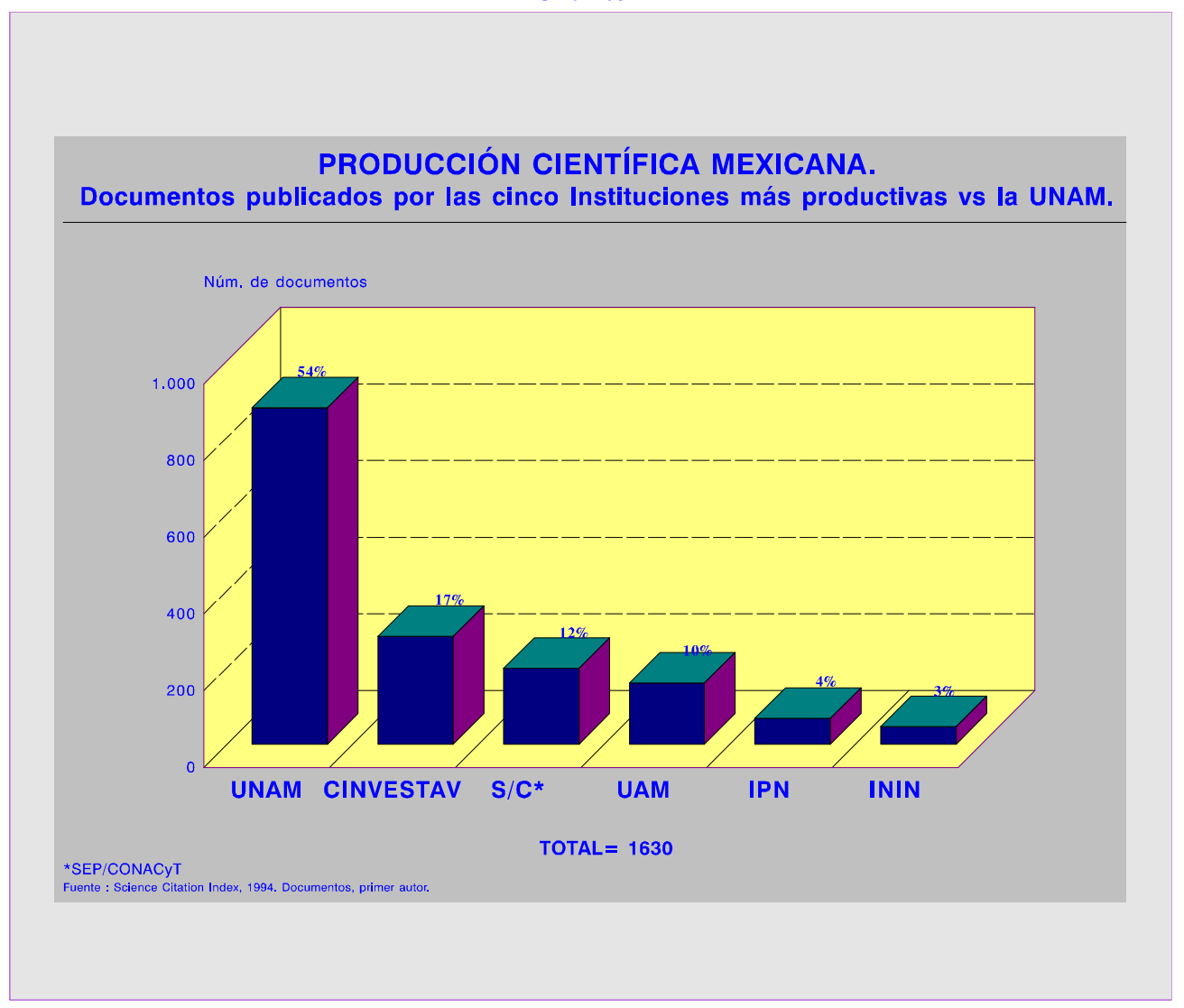


Indicadores científicos: evaluaciones negativas proposiciones positivas 75

La Universidad Nacional A utónoma de México es la institución con mayor número de "Investigadores Nacionales", estímulo que otorga desde 1984 el gobierno mexicano a los más destacados investigadores en reconocimiento a su labor académica. Según datos de CO N A CyT el Sistema N acional de Investigadores tiene un total de 5500 integrantes divididos en: C andidatos 26\%, Nivel I $52.4 \%$, Nivel II $14.2 \%$ y en el Nivel III $6.6 \%$.

La institución con mayor número de miembros en el SIN es la UNAM con el $33 \%$, seguido por 13 instancias más en donde la institución más alta sólo alcanza un $6.1 \%$ y el grupo más alto (universidades públicas de los estados) el 16\%, asimismo varios de sus científicos se encuentran entre los autores más citados en Latinoamérica (UNA M, 1988).

Si se compara a la UNA M con las cinco instituciones nacionales que aparecen en el SC I como las más productivas sean estas de carácter público, privado 0 académico, da como resultado que la UNAM obtiene el porcentaje más alto, de un 54\% (ver Gráfico1) pero si además se compara con la institución inmediata jerarquizada en orden decreciente, la UNA M obtiene un $76 \%$.

\section{El Subsistema de la Investigación Científica}

La Coordinación de la Investigación Científica (C IC) es el órgano ejecutor de las decisiones tomadas por el Consejo Técnico dela Investigación Científica -órgano colegiado de autoridad que cumple las atribuciones que le señala la Legislación Universitaria- y sirve de apoyo en su función de coordinar e impulsar las labores de institutos y centros (1992, Informe UNAM) en el Subsistema de la Investigación Científica (SIC). La formación de los primeros grupos de investigación científica en la U NA M tiene su antecedente en el siglo pasado, sin embargo, no es sino hasta 1929 cuando secrean oficialmente los primeros tresinstitutos.

En la página siguiente se presentan en la tabla 1 los datos tabulados con las siguientes variables: año de creación de cada una de las instancias que conforman el subsistema, antecedente de creación a través del año correspondiente cuando éste existe, tal es el caso de 10 dependencias, no mbre actual de las dependencias y para finalizar, el número de investigadores que según la fuente consultada, los conforman.

Como se observa en la tabla 1 el Subsistema de la Investigación Científica de la UNA M está conformado por dieciséis institutos, ocho centros y cinco programas en donde más de novecientos investigadores cultivan una amplia variedad de disciplinas en la ingeniería, las ciencias naturalesy las exactas. La investigación científica y tecnológica se realiza tanto en las instalaciones ubicadas en la Ciudad Universitaria, como en estaciones de campo, observatorios, buques o ceano gráficos, laboratorios y servicios nacionales dela propia universidad, localizados en diversas regiones de la República Mexicana. 
76 Investigación Bibliotecológica v. 12 N o. 25 julio/ diciembre de 1998

Tabla 1

Institutos Centros y Programas del SIC en la UNAM

\begin{tabular}{|c|c|c|c|}
\hline $\begin{array}{l}\text { Año de } \\
\text { creación }\end{array}$ & Antecedente & Dependencia & $\begin{array}{c}\text { Número de } \\
\text { investigadores }\end{array}$ \\
\hline 1929 & 1883 & Instituto de A stronomía & 28 \\
\hline 1929 & 1883 & Instituto de Biología & 64 \\
\hline 1929 & 1886 & Instituto de G eología & 51 \\
\hline 1938 & & Instituto de G eografía & 38 \\
\hline 1938 & & Instituto de Física & 125 \\
\hline 1941 & & Instituto de Q uímica & 53 \\
\hline 1942 & & Instituto de Matemáticas & 57 \\
\hline 1945 & & Instituto de Investigaciones en Biomédicas & 49 \\
\hline 1945 & & Instituto de G eofísica & 53 \\
\hline 1971 & & Centro de Información Científica y Humanística & 1 \\
\hline 1971 & & Centro de Instrumentos & 4 \\
\hline 1976 & 1958 & $\begin{array}{l}\text { Instituto de Investigaciones en Matemáticas } \\
\text { Aplicadas y en Sistemas }\end{array}$ & 44 \\
\hline 1976 & & Instituto de Ingeniería & 68 \\
\hline 1977 & & Centro de Ciencias de la atmósfera & 28 \\
\hline 1979 & 1967 & Instituto de Investigaciones en Materiales & 52 \\
\hline 1980 & & Centro de Investigación Sobre Fijación del Nitrógeno & 16 \\
\hline 1981 & 1973 & Instituto de Ciencias del Mar y Limnología & 58 \\
\hline 1981 & & Programa Universitario de Alimentos & $*$ \\
\hline 1982 & & Instituto de Biotecnología & 64 \\
\hline 1982 & & Programa Universitario de Energía & $*$ \\
\hline 1985 & 1983 & Centro para la innovación Tecnológica & 2 \\
\hline 1985 & 1979 & Instituto de Fisiología C elular & 41 \\
\hline 1987 & & Centro Universitario de Comunicación de la Ciencia & 2 \\
\hline 1988 & 1967 & Instituto de Ciencias Nucleares & 12 \\
\hline 1988 & & Centro de Ecología & 37 \\
\hline 1988 & 1981 & Programa Universitario de Investigación en Salud & $*$ \\
\hline 1990 & & Programa Univ. de Inves. y D esarrollo Espacial & $*$ \\
\hline 1991 & & Programa Universitario de Medio ambiente & $*$ \\
\hline 1993 & & Centro de Neurobiología & 12 \\
\hline
\end{tabular}

日 Centro de Neurobiología fue agregado a la tabla origina, as conø e núnæro de investigadores

* No se arta con el dato.

Fuerte UNAM. Menøria 1995. UNAM. CIC. Institutos Centros y Proganæs 1988 
Indicadores científicos: evaluaciones negativas proposiciones positivas 77

\section{El personal académico del SIC}

De acuerdo con la Legislación Universitaria (UNA M, 1987) en la Universidad Nacional los investigadores tienen a su cargo las labores de investigación y docencia y pueden ocupar cualquiera de las siguientes categorías:

1- Auxiliar

2- A sociado

3- Titular

En cada categoría existen tres niveles: "A", "B" y " $\mathrm{C}$ ".

El personal académico en el SIC está integrado por 1890 académicos, de ellos, 899 son técnicos y 991 son investigadores en un porcentaje de 48\% para los primeros y 52\% para los segundos. En la categoría de investigador, hasta el momento no existe personal contratado en el nivel de auxiliar.

\begin{tabular}{|c|c|c|c|c|}
\hline \multicolumn{5}{|c|}{ Tabla 2} \\
SIC. Personal A cadémico por Cateqoría y Nivel \\
\hline Investigador & Técnico \\
\hline Asociado & Titular & A auxiliar & A sociado & Titular \\
\hline 366 & 625 & 42 & 500 & 357 \\
\hline
\end{tabular}

Furte UNAM, DGPYP. enero de 1995.

Este grupo está conformado aproximadamente en un 37\% por investigadores asociados y en un $65 \%$ por investigadores titulares.

\begin{tabular}{|c|c|c|c|c|c|}
\hline \multicolumn{7}{|c|}{ Tabla 3 } \\
\hline \multicolumn{7}{|c|}{ TIC. Investigadores por C ategoría v Nivel } \\
\hline A sociado & B & C & A & B & C \\
\hline 8 & 53 & 305 & 254 & 171 & 200 \\
\hline \multicolumn{3}{|c|}{ TOTAL: 366} & TOTAL: 625 \\
\hline
\end{tabular}

Furte UNAM, DGPYP. enero de 1995.

D entro de la comunidad el mayor porcentaje en el nivel de investigadores contratados corresponde a la figura de investigador asociado " $\mathrm{C}$ " con un $31 \%$, seguido muy de cerca por el investigador titular " $A$ " con un $26 \%$. Los datos sobre el personal académico tienen gran movilidad, pero en relación con sus porcentajes totales en el periodo, por ejemplo, de un año el número no es significativo. Para este trabajo los datos sobre los investigadores se obtuvieron de la información correspondiente a 1995.

Cuando se requiere aplicar indicadores para conocer el impacto de la obra publicada, la producción, el factor de impacto de las revistas en donde publican los investigadores o cualquier otro indicador relacionado con éstos, la C IC concentra a sus investigadores en veintiún dependencias y 8 áreas. 
78 Investigación Bibliotecológica v. 12 N o. 25 julio/ diciembre de 1998

A continuación se presentan las dependencias consideradas por la Coordinación para esta clase de estudios:

Tabla 4

\begin{tabular}{|c|c|}
\hline DEPENDENCIA & ABREVIATURA \\
\hline 1- CENTRO DE CIENCIAS DE LA ATMÓ SFERA & $\mathrm{CCA}$ \\
\hline 2- CENTRO DE ECOLOGÍA & $\mathrm{CE}$ \\
\hline 3- CENTRO DE INSTRUMENTOS & $\mathrm{CI}$ \\
\hline $\begin{array}{l}\text { 4- CENTRO DE INVEST IGACIÓN SOBRE FIJACIÓN DEL } \\
\text { NITRÓGENO }\end{array}$ & CIFN \\
\hline 5- CENTRO DE NEUROBIOLOGÍA & $\mathrm{CN}$ \\
\hline 6- INSTITUTO DE ASTRONOMÍA & IA \\
\hline 7- INSTITUTO DE BIOLOG ÍA & IB \\
\hline 8- INSTITUTO DE BIOTECNOLOGÍA & IBt \\
\hline 9- INSTITUTO DE CIENCIAS DEL MAR Y LIMNOLOG ÍA & ICML \\
\hline 10- INSTITUTO DE CIENCIAS NUCLEARES & ICN \\
\hline 11- INSTITUTO DE FÍSICA & IF \\
\hline 12- INSTITUTO DE FISIOLOGÍA CELULAR & IFC \\
\hline 13- INSTITUTO DE GEOFÍSICA & IGf \\
\hline 14- INSTITUTO DE GEOG RAFÍA & $\mathrm{IGq}$ \\
\hline 15- INSTITUTO DE GEOLOGÍA & IGl \\
\hline 16- INSTITUTO DE ING ENIERÍA & II \\
\hline 17- INSTITUTO DE INVESTIGACIONES BIO MÉDICAS & IIB \\
\hline 18- INSTITUTO DE INVESTIGACIONESEN MATERIALES & IIM \\
\hline $\begin{array}{l}\text { 19- INSTITUTO DE INVESTIGACIONES EN MATEMÁTICAS } \\
\text { APLICADAS Y EN SISTEMAS }\end{array}$ & IIMAS \\
\hline 20- INSTITUTO DE MATEMÁTICAS & $\mathrm{IM}$ \\
\hline 21-INSTITUTO DE Q UÍMICA & IQ \\
\hline
\end{tabular}

En concordancia con las políticas antes mencionadas, las áreas se conformaron agrupándolas de acuerdo con los siguientes criterios:

\begin{tabular}{|l|l|}
\hline \multicolumn{2}{|c|}{ Tabla5 } \\
\hline \multicolumn{1}{|c|}{ ÁREA } & \multicolumn{1}{c|}{ DEPENDENCIAS } \\
\hline 1- ASTRONOMÍA & 1- IA \\
\hline \multirow{2}{*}{ 2- BIO LOG ÍA } & 2-CE \\
& 3-CIFN \\
\hline & 4 - IB \\
\hline
\end{tabular}




\begin{tabular}{|c|c|}
\hline \multicolumn{2}{|c|}{$\begin{array}{c}\text { Tabla } 5 \\
\text { (continuación) }\end{array}$} \\
\hline ÁREA & DEPENDENCIAS \\
\hline \multirow{4}{*}{ 3- BIO MÉDICA } & 5- $\mathrm{CN}$ \\
\hline & 6- IBt \\
\hline & 7- IIB \\
\hline & 8- IFC \\
\hline \multirow{5}{*}{ 4- CIEN CIAS DE LA TIERRA } & 9- CCA \\
\hline & 10- ICML \\
\hline & 11- IGf \\
\hline & 12- IGg \\
\hline & 13- IGl \\
\hline \multirow{3}{*}{ 5- FÍSICA } & 14- ICN \\
\hline & 15- IF \\
\hline & 16- IIM \\
\hline \multirow{2}{*}{$\begin{array}{l}\text { 6- ING ENIERÍA Y } \\
\text { TECNOLÓ G ICAS }\end{array}$} & 17- CI \\
\hline & 18- II \\
\hline \multirow[t]{2}{*}{ 7- MATEMÁTICAS } & 19- IIMA S \\
\hline & 20- IM \\
\hline 8- QUÍMICA & 21- IQ \\
\hline
\end{tabular}

\section{A nálisis de los resultados}

T endencias de la producción científica generada por los investigadores del SIC-U N A M

Esta comunidad tiene una productividad reconocida. El producto informativo aportado por los investigadores del SIC puede ser considerado como la mayor contribución que se genera en el país en el campo de la investigación científica. D e acuerdo con el SaienœCitation Index consultado en los últimos cinco años, el porcentaje de la UNA M en producción es el más alto y el porcentaje de la producción del SIC referida a la U NA M es de más de un 70 por ciento. Con el propósito de observar la evolución anual de los documentos publicados por investigador en un periodo de cinco años que van de 1990 a 1994, se ha realizado una distribución representada en el Gráfico2. La primera columna representa 
la producción de México en un cien por ciento durante un año determinado, la segunda columna ofrece información sobre el porcentaje de la producción de la UNAM respecto a la producción de México y por último la tercera columna se refiere al porcentaje de la producción del Subsistema de la Investigación Científica referida a la UNAM.

\section{Gráfico 2}

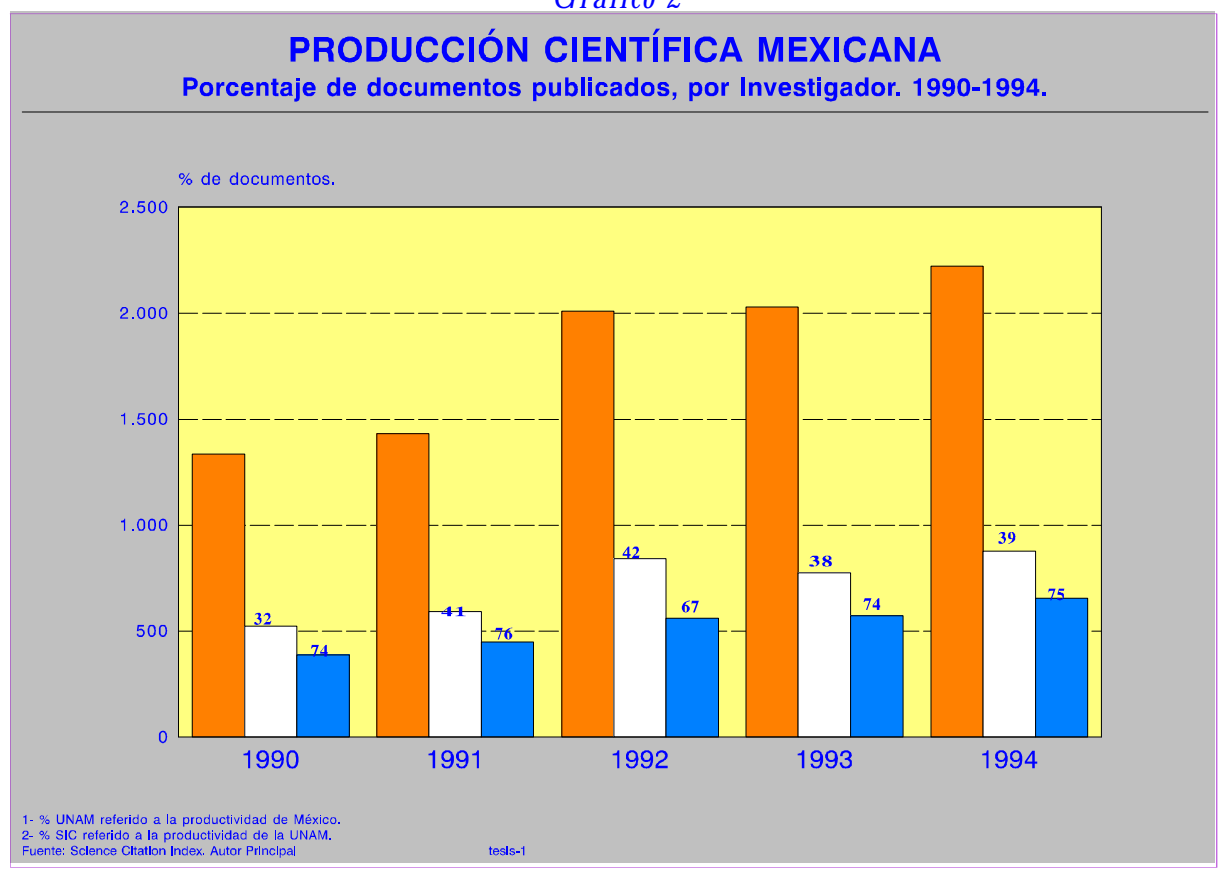

Si se observa el primer bloque de 3 columnas en el año de 1990, la segunda columna representa la producción de la UNA M respecto a todo el país con un $32 \%$. La tercera columna representa la producción del Subsistema de la Investigación Científica referido a la UNA M, éste alcanza un 74\% de la producción científica en esta institución.

Para el año de 1991 la UNA M obtiene un 41\% frente al resto del país, y el SIC un $76 \%$ referido a la UNA M, por lo tanto respecto al año anterior se puede observar un aumento significativo, tanto en la producción de la UNA M, como en la del SIC.

En 1992 la UNA M obtiene un 42\% respecto a todo México y el Subsistema un $67 \%$ de la producción generada en la UNA M. En este año la producción de México aumenta de modo notable, la UNA M con un ligero aumento casi mantiene el porcentaje del año anterior y el SIC tiene un descenso de un $12 \%$ en su producción. 
Indicadores científicos: evaluaciones negativas proposiciones positivas 81

En los años 1993 y 1994 la producción de la UNAM frente al país baja ligeramente -38\% y 39\%- en relación con los dos años anteriores que fue de 41 y 42 por ciento, sin embargo, la producción del SIC durante 1993 y 1994 recupera en parte el nivel obtenido en 1990 y 1991, con un 74\% y un 75\% respectivamente.

\section{C aracterísticas del comportamiento de la producción científica generada por los investigadores del SIC-U N A M}

\section{L as publicaciones y sus autores}

La producción de los Investigadores del Subsistema por D ependencia se encuentra publicada en diversos documentos, aunque no en los mismos porcentajes, es posible observar que en aquellas disciplinas que tienen una vinculación directa con actividades necesarias para resolver problemas inmediatos en la construcción y mantenimiento de la infraestructura física del país, en la exploración y explotación de sus recursos materiales y en la protección ante lo s fenómenos naturales capaces de poner en riesgo a los hombres y sus bienes (Institutos de G eofísica, G eografía, G eología e Ingeniería) se experimenta un desarrollo diferente del observado por otros institutos que se encuentran orientados en forma más preponderante a la investigación científica básica (Esteva, L. 1990).

De la orientación que tengan estas instituciones depende en mucho el tipo de documento en donde publica este grupo, en ingeniería, por ejemplo, el número de reportes o proyectos de investigación rebasa al número de títulos de revistas 0 en otras disciplinas como G eografía, cuyas características imprimen, al tipo de documento en donde publican los investigadores, un perfil acorde con su objeto de estudio; la producción bibliográfica se manifiesta con mayor frecuencia en mapas, cartografías, planos, cartas y en un porcentaje menor en revistas.

Al tener como fuente el curriculum de los investigadores y en correspondencia a lo anteriormente señalado, en la tabla 6 es posible observar, que los porcentajes más altos de publicación en documentos en general, es decir, sin separar el número de artículos en revistas, corresponden a cuatro dependencias, éstas son: el Instituto de Ingeniería con el porcentaje más alto del SIC 72\% correspondiente a to do tipo de documento y $28 \%$ a la de publicación en revistas; a continuación el Instituto de G eografía con un 64\% de publicación en diversos documento y y 36\% en revistas; enseguida el Instituto de G eología con un 63\% de publicación en diferentes documentosy solamente un 37\% en revistas y por último el Centro de Instrumentos con un $62 \%$ de documentos publicados y solamente un 38\% de artículos publicados en revistas. En el otro extremo no deja de llamar la atención que el Instituto de Q uímica publique un 94\% en revistas y solamente un $6 \%$ en otro tipo de documentos como pudieran ser proyectos vinculados con la industria. 
82 Investigación Bibliotecológica v. 12 N o. 25 julio/ diciembre de 1998

\begin{tabular}{|c|c|c|}
\hline \multicolumn{3}{|c|}{ Tabla 6} \\
\hline Dependencias & $\begin{array}{c}\text { Porcentaje de } \\
\text { documentos }\end{array}$ & $\begin{array}{l}\text { Porcentaje de } \\
\text { artículos }\end{array}$ \\
\hline II & 72 & 28 \\
\hline Gq & 64 & 36 \\
\hline Gl & 63 & 37 \\
\hline CI & 62 & 38 \\
\hline CIFN & 58 & 42 \\
\hline IIMAS & 58 & 42 \\
\hline IIM & 44 & 56 \\
\hline CN & 43 & 57 \\
\hline ICML & 43 & 57 \\
\hline CCA & 36 & 64 \\
\hline CE & 34 & 66 \\
\hline Gf & 34 & 66 \\
\hline IA & 31 & 69 \\
\hline IB & 31 & 69 \\
\hline IBt & 31 & 69 \\
\hline IM & 31 & 69 \\
\hline IIB & 26 & 74 \\
\hline ICN & 25 & 75 \\
\hline IF & 22 & 78 \\
\hline IFC & 21 & 79 \\
\hline IQ & 6 & 94 \\
\hline TOTAL & 39525 & 25159 \\
\hline
\end{tabular}

El universo de investigadores estudiado en este trabajo ha producido un total de 39525 documentos, de los cuales el 63\% corresponde a artículos publicados en revistas científicas.

La revista científica como publicación periódica primaria tiene una serie de características, entre ellas, es el medio propicio para que a través del tiempo se forme una memoria colectiva de ese conocimiento científico, es también un medio de enorme valor para la formación y la enseñanza de todo individuo relacionado con el aprendizaje, permite la comunicación, aun en aquellas situaciones en las que se carece de infraestructura para utilizar medios electrónicos, es uno de los soportes materiales de todo conocimiento, su contenido está por lo general orientado a campos o tópicos concretos de la ciencia y finalmente la recuperación de la información generada es bastante accesible por medio de las publicaciones periódicas secundarias como son índices y resúmenes bibliográficos, catálogos y kardex en bibliotecas, catálogos colectivos, bibliografías, así como en bases de datos y medios electrónicos. 
D ebido a estas características la revista científica se ha convertido en la colección más consultada en las bibliotecas especializadas. 0 tro punto que hay que considerar es que la revista al aparecer en todas las dependencias como un elemento identificable, es posible de medir.

Si se contempla un total global en el Subsistema de la Investigación C ientífica, el documento con mayor representatividad es la revista científica, ya que el 71 por ciento de las dependencias publica más en revistas que en cualquier otro documento y el 29 por ciento publica menos en revistas y más en otro tipo de documento, sin que esto signifique que la revista esté excluida en alguna de las disciplinas del Subsistema (ver Gráfiø3).

\section{Gráfico3}

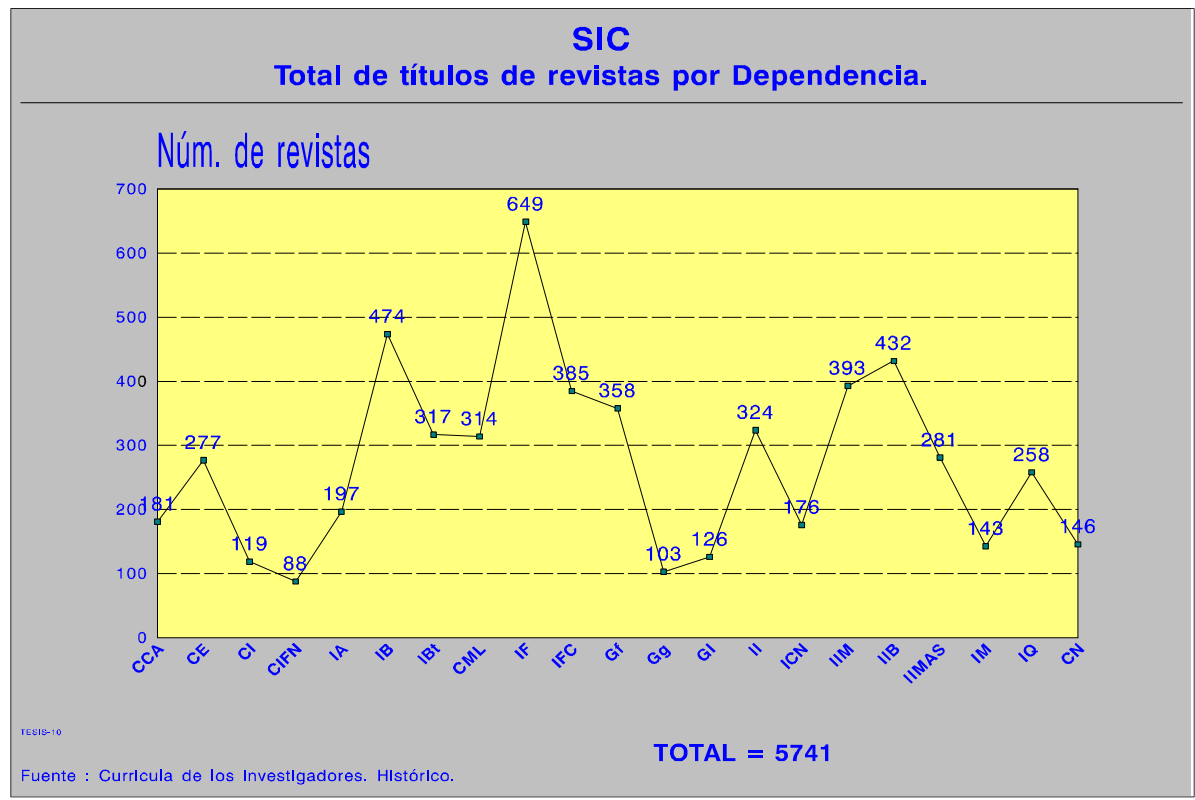

El proceso de medir el comportamiento de la producción científica generada por los investigadores del SIC -UN A M a través de su obra publicada contiene una serie de variables que caracterizan a ese comportamiento dentro de los siguientes campos:

*ítulos de revistas en donde publican

* artículos publicados en los títulos antes mencionados

* impacto que su obra publicada tiene en otros investigadores. 
84 Investigación Bibliotecológica v. 12 N o. 25 julio/ diciembre de 1998

\section{Títulos de revistas}

Las fuentes de información a través de las cuales se difunde el producto informativo generado por los investigadores del SIC, tienen variados matices, pero en un muy alto porcentaje reflejan impacto y prestigio profesional en la comunidad científica internacional. La cantidad de estas fuentes varía de acuerdo con el área temática de pertenencia.

El total de títulos de revistas científicas - extraídos de los currículos de losinvestigadores del SIC- en donde publican éstos es de 5741. (Ver Tabla 1 del anexo).

Las dependencias que publican en una mayor variedad de títulos, es decir, que no tienen un núcleo de revistas sino que muestran una mayor dispersión, son 7 y en ellas aparece más del 50\% de los títulos traslapados.

Estos institutos son: el IF, el IB, el IIM, IFC, IG F, II, IBt, entre todos ellos suman un total de 2900 títulos.

En cambio las dependencias con un menor número de títulos son: IM, Gl, $\mathrm{CI}, \mathrm{G}$ g, CIFN , con un $2 \%$, en estas dependencias no existe una gran dispersión, ya que sus artículos están publicados en muy pocos títulos (ver Gráfiø 4).

\section{Gráfico 4}

SIC.Distribución de revistas donde publican los investigadores. En orden jerárquico por Dependencia.

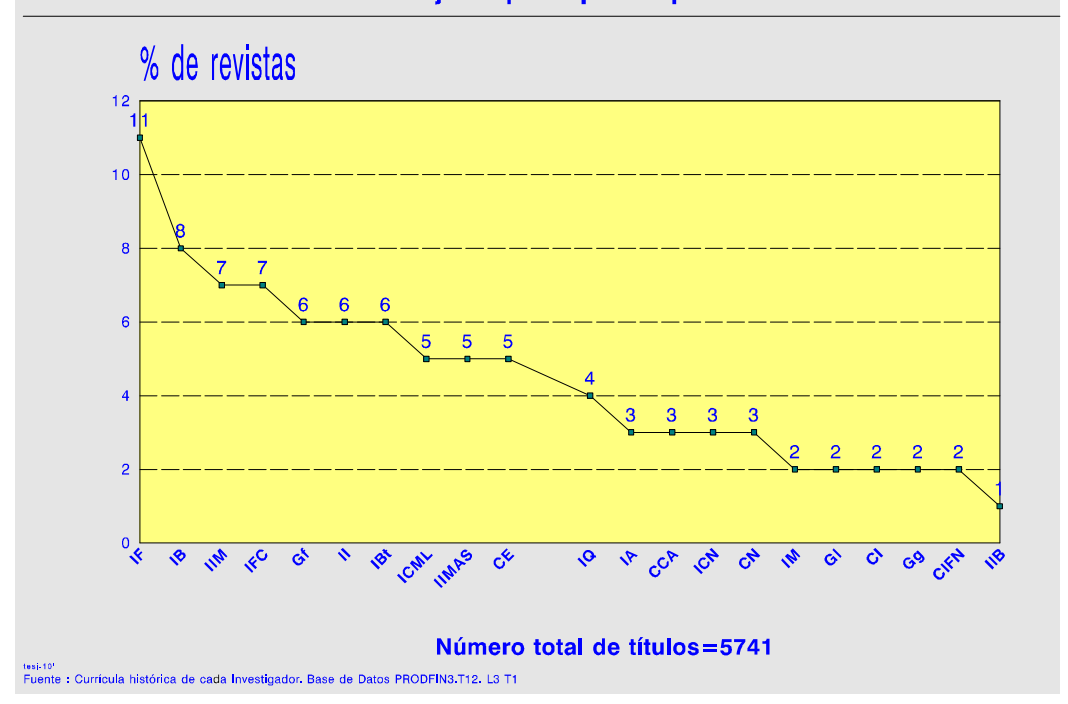

El peso de unas dependencias sobre otras hace que el análisis por áreas tenga otra expresión de acuerdo con el esquema de la CIC, las áreas no tienen el mismo número de dependencias agrupadas, además respetando ese orden se separaron como únicos, a los Institutos de A stronomía y Q uímica. En la Tabla1del 
anexo es posible observar que mientras en el área de Física se publica en 1218 títulos diferentes, el área de matemáticas sólo publica en 424 títulos. Respecto a cantidades el área Biomédica y Física publican en un mayo r número de revistas en comparación con otras áreas, seguidos por Ciencias de la Tierra y Biología y en un porcentaje bastante meno r por Ingeniería y Matemáticas (ver Gráfico5).

\section{Gráfico5}

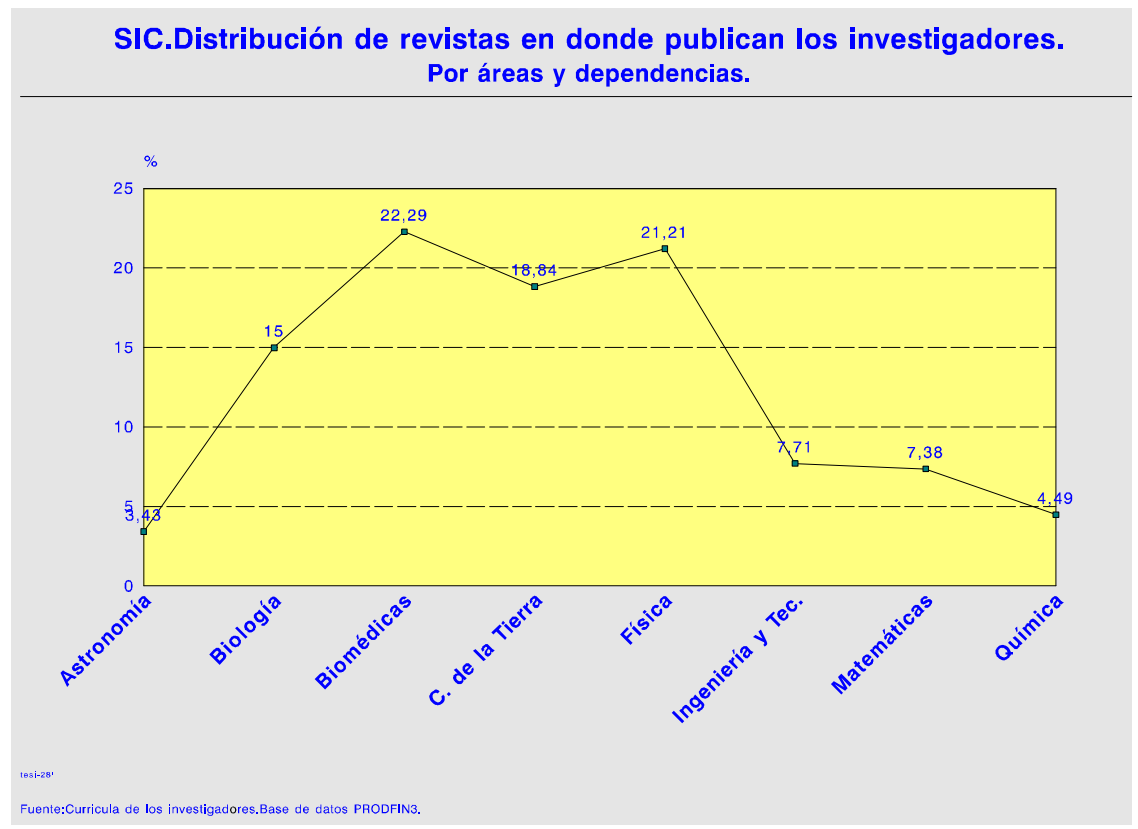

En cuanto a la calidad dela revista en donde se publica, un indicador frecuentemente utilizado es el Factor de Impacto (FI). Por sí solo la calidad del artículo no determina el FI, ya que éste tiene que aso ciarse además de a la buena calidad, también al prestigio del autor, o a otros factores de tipo condicionante como son el área temática a la cual se dedica el artículo, que puede corresponder a uno de los principales frentes de investigación de gran actividad en la comunidad científica mundial, o a lo incipiente de un tema de investigación o tal vez a otros motivos. El FI tiene numerosas aplicaciones, y tratándose de una evaluación, ésta debe ajustarse al objetivo combinándolo con otros indicadores tanto cuantitativos como cualitativos. En la identificación del FI de las revistas en donde publican los investigadores del SIC se encontró que la suma del número de títulos de revistas por dependencias, nos da un total de 5741, de los cuales el 36\% correspondiente a 2040 títulos tienen Factor de Impacto (FI), mientras que el porcentaje entre las que no lo tienen es del 64\%, que correspondea 3701 títulos. 
86 Investigación Bibliotecológica V. 12 N o. 25 julio/ diciembre de 1998

Para este trabajo el FI se obtuvo utilizando como fuente el Journal Citation Reports(JCR) 1992, sin embargo, en un análisis más extenso existe la posibilidad de analizar cada uno de los 3701 títulos que no aparecen en este índice para conseguir su FI de acuerdo con el método utilizado en la India (Sen, B, 1998.) en el que una vez aplicada la fórmula se obtiene el FI de esos títulos, independientemente de que el JCR no los reporte.

Gráfico 6

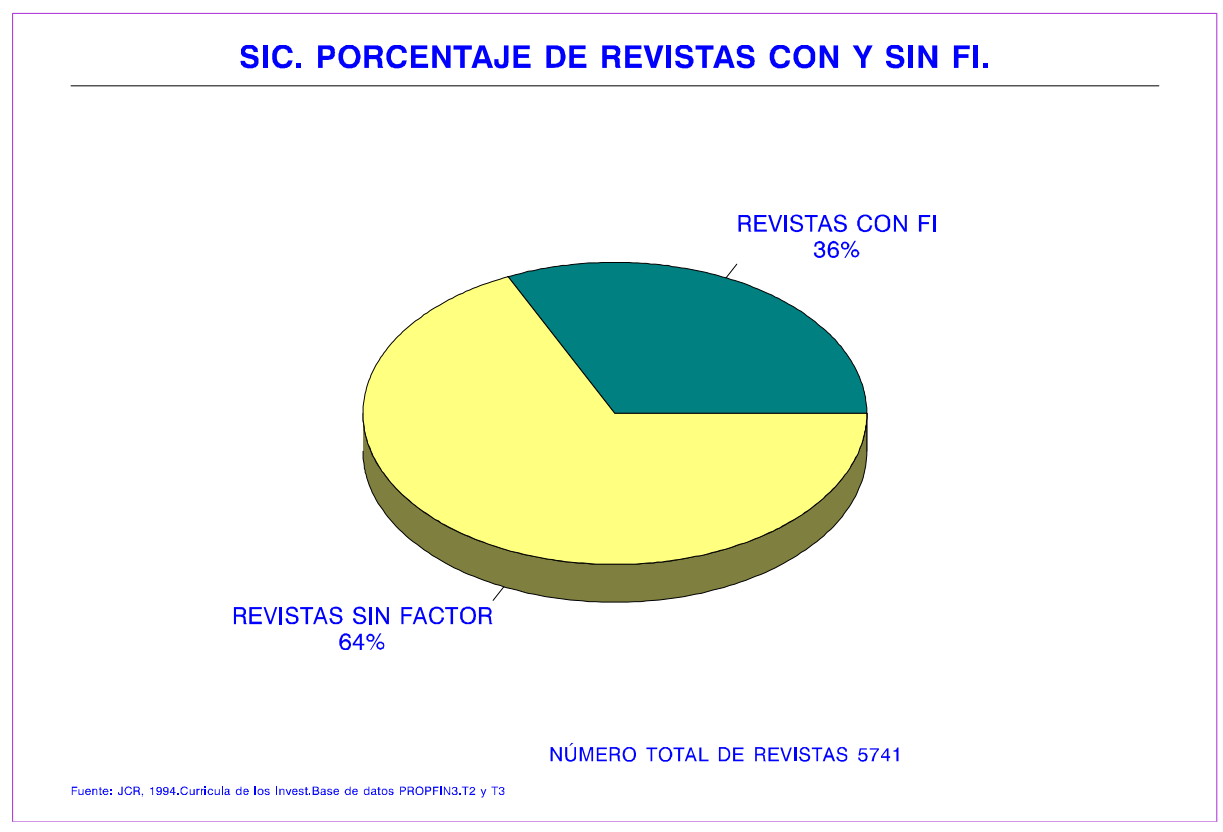

Si se correlacionan las variables: número de títulos de revistay número de revistas con FI, el porcentaje de revistas con FI, en orden jerárquico por dependencia muestra que de los 21 institutos y centros que conforman la muestra, tres son los que tienen el porcentaje más alto de revistas con FI. Estas dependencias son CIFN con un 58\%, el IBt con un 53\%, el IFC con un 53\%.

Los 4 institutos con el porcentaje más bajo en el grupo de revistas con FI son: Gf con un 20\%, II con un 19\%, Gl con un 15\%, y el G g con $6 \%$.

Si se traza una línea resultado de la división entre el número de revistas con FI y el total del número de revistas en el subsistema se obtiene un porcentaje promedio por área, que relacionado con el porcentaje real que obtuvo cada dependencia, a partir de los datos de los currículos de los investigadores del Subsistema, podemos observar cuales dependencias están abajo de ese promedio (ver Gráfico 7). 
Gráfico 7

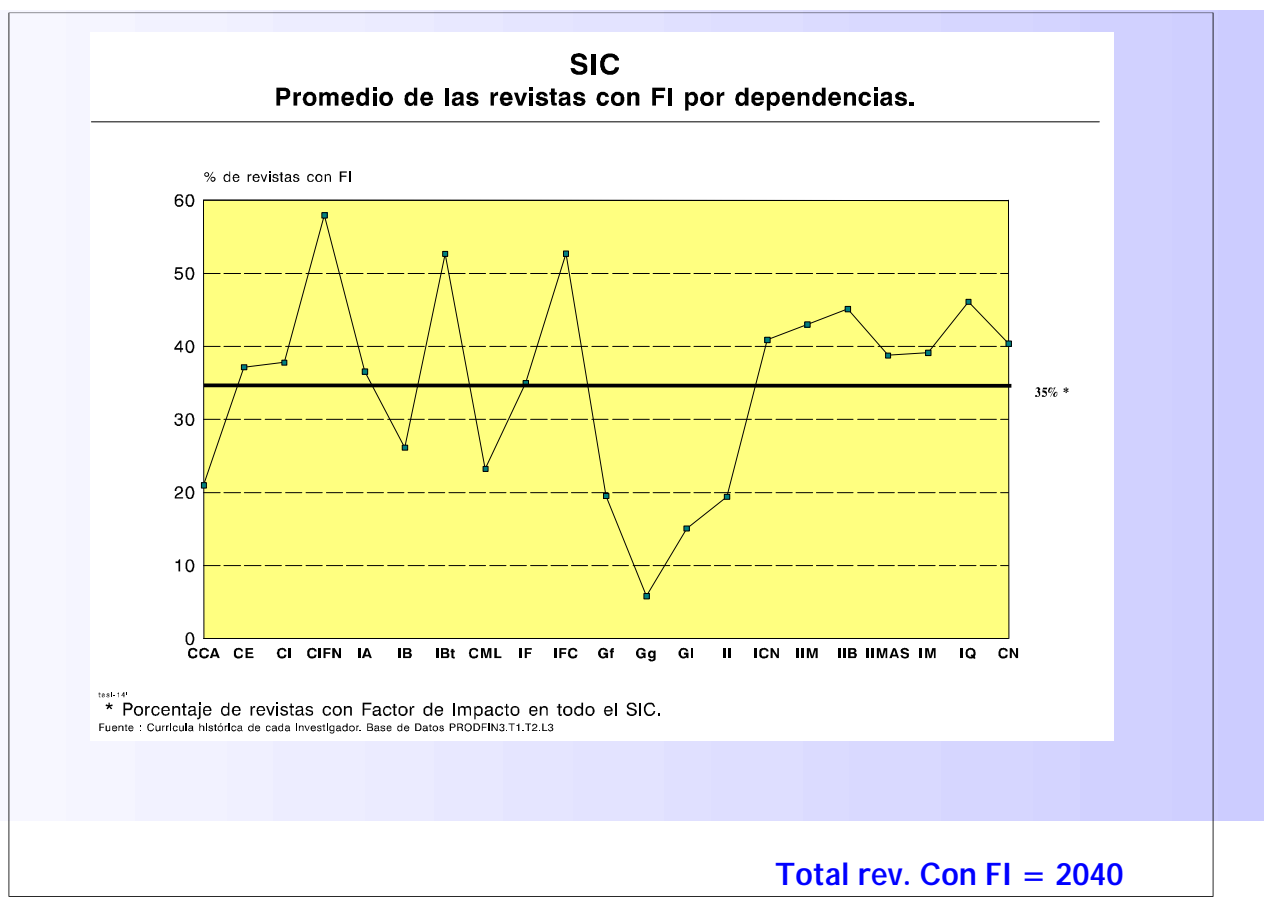

También se analizó a partir del total de revistas sin FI el porcentaje de éstas por dependencia. En este caso el total de revistas sin FI fue de 3701 en el universo de 5741. Al igual que para las revistas con FI se correlacionaron dos variables: número de revistas y número de revistas sin FI.

En el resultado se puede advertir que son cuatro las dependencias que más publican en revistas sin FI: Gg 94\%, Gl 85\%, II 81\%, Gf 80\%.

Para obtener un valor que tuviera un concepto más distributivo en toda la muestra sin que el resultado estuviera viciado por aquellos investigadores que producen más, se obtuvo la mediana de las revistas que tenían FI, asignando a cada dependencia este valor. La mediana es una medida de tendencia central que nos indica hacia donde están concentrados los datos, pero a diferencia del promedio es menos sensible ante datos u observaciones extremas. En la tabla que se presenta a continuación (Tabla 7) es posible observar la mediana del Factor de Impacto en revistas con este valor por cada una de las $21 \mathrm{D}$ ependencias del SIC analizadas en este trabajo. 
88 Investigadón Bibliotecológica v. 12 N o. 25 julio/ diciembre de 1998

\section{Gráfico 8}

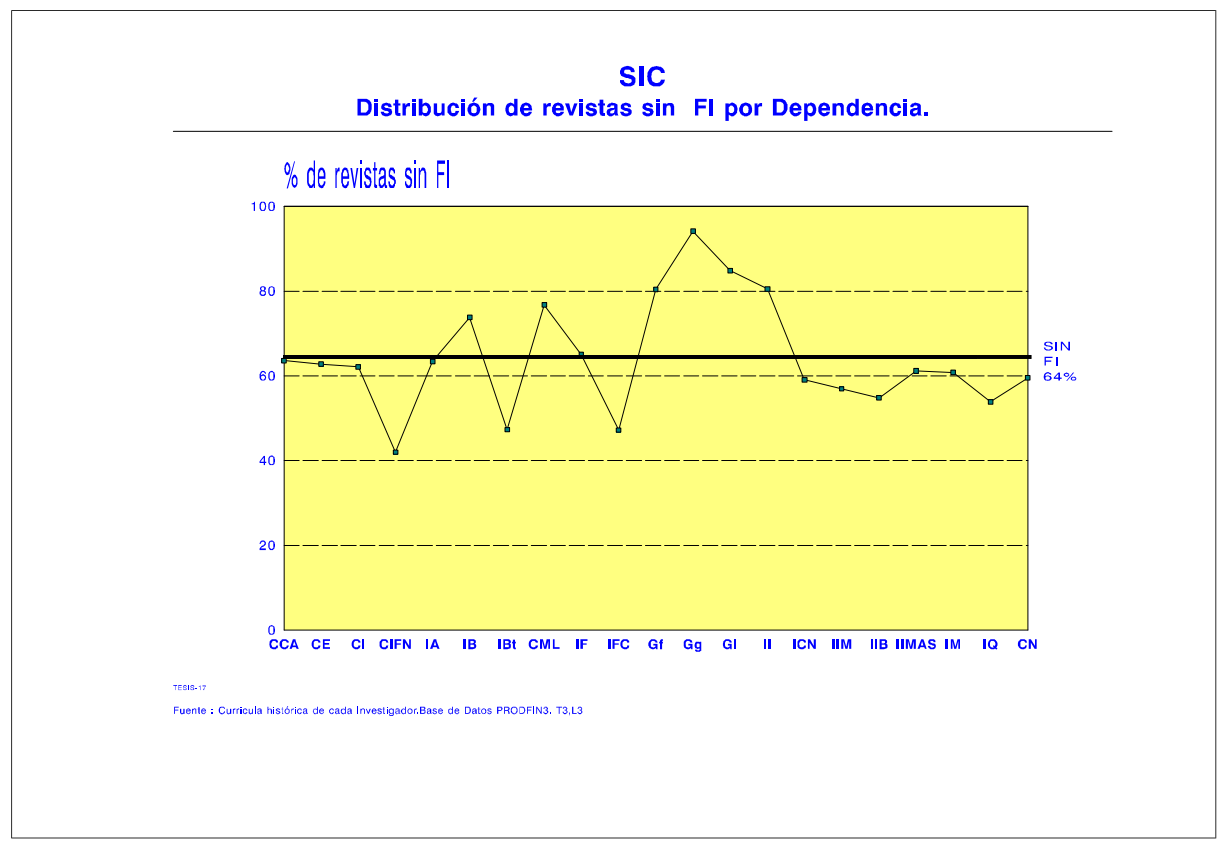

Tabla 7

\begin{tabular}{|c|c|}
\hline DEPENDENCIA & MEDIANA \\
\hline $\mathrm{CIFN}$ & 3.0640 \\
\hline $\mathrm{Gq}$ & 2.78 \\
\hline IBt & 2.5280 \\
\hline IA & 2.0325 \\
\hline IFC & 1.9630 \\
\hline IIB & 1.9460 \\
\hline $\mathrm{CN}$ & 1.7660 \\
\hline IQ & 1.3320 \\
\hline $\mathrm{CCA}$ & 1.2375 \\
\hline Gf & 1.1660 \\
\hline IF & 1.1340 \\
\hline $\mathrm{Gl}$ & 1.1300 \\
\hline CI & 1.1120 \\
\hline IIM & 1.0510 \\
\hline IIMAS & 0.7770 \\
\hline CE & 0.6920 \\
\hline II & 0.5820 \\
\hline IB & 0.5585 \\
\hline ICN & 0.5565 \\
\hline ICML & 0.3910 \\
\hline IM & 0.3700 \\
\hline
\end{tabular}

Furte Curiala de los investigadores J CR 1992. L3. 
Indicadores científicos: evaluaciones negativas proposiciones positivas $\mathbf{8 9}$

La mediana del Factor de Impacto en este grupo muestra que en siete dependencias la mediana es menos de uno, en diez dependencias la mediana se encuentra entre 1 y 1.9, en tres dependencias la mediana está entre 2 y 2.7, y por encima de 3 solamente se encuentra una dependencia.

\begin{tabular}{|l|l|}
\hline \multicolumn{1}{|c|}{ FI de la revista } & \multicolumn{1}{c|}{ Núm. de Dependencias } \\
\hline$>$ de tres & 1 D ependencia \\
\hline Entre 2.78 y 2.03 & 3 D ependencias \\
\hline Entre 1.98 y 1.05 & 10 D ependencias \\
\hline$<$ de uno & 7 D ependencias \\
\hline
\end{tabular}

El grupo mayor se encuentra entre las 10 dependencias comprendidas entre 1.9630 y 1.0510 de FI en las revistas en donde publican los investigadores.

El FI más elevado en el SIC fue de 37.1600 y considerando el más elevado por dependencia, éste fue de más de 37 para tres dependencias, de 20 para una, de más de 19 para trece dependencias y menor de 10 en cuatro dependencias. El FI más elevado por dependencia se muestra en la tabla 9: en orden jerárquico por grupos.

Tabla 9

\begin{tabular}{|c|l|l|}
\hline DEPEN DENCIA & \multicolumn{1}{|c|}{ FI } & \\
\hline IBt & 37.16 & CLINICAL RESEA RCH \\
\hline IIB & 37.16 & \\
\hline IFC & 37.16 & \\
\hline IF & 20 & ADV. NUCL. PHY SICS \\
\hline CE & 19.6070 & SCIENCE \\
\hline IB & 19.6070 & \\
\hline CN & 19.6070 & \\
\hline ICML & 19.6070 & \\
\hline Gf & 19.6070 & \\
\hline G & 19.6070 & \\
\hline Gl & 19.6070 & \\
\hline II & 19.6070 & \\
\hline IA & 19.3370 & NATURE \\
\hline CIFN & 19.3370 & \\
\hline IIM & 19.3370 & \\
\hline IIMAS & 19.3370 & \\
\hline IQ & 19.3370 & \\
\hline ICN & 7.29 & PHYS. REV. LETTERS \\
\hline CCA & 3.8520 & GENETICS \\
\hline CI & 3.3030 & ASTROPHY S. JO UR. \\
\hline IM & 2.1040 & PHYSICAL REVIEW \\
\hline
\end{tabular}

Furte Curiala histórica de los investigadores J CR 1992 T8. 
90 Investigación Bibliotecológica v. 12 N o. 25 julio/ diciembre de 1998

Además de la mediana, otra medida utilizada con frecuencia es el FI Promedio. Cuando el promedio se aplica a otros indicadores el resultado puede ser altamente representativo, pero para el FI no es recomendable, ya que la información puede presentar un sesgo y por lo tanto el resultado puede ofrecer una medida menos confiable.

Este resultado puede estar viciado por diversos motivos, entre ellos por ejemplo que a la dependencia esté adscrito un investigador que publica en revistas de gran impacto, lo que hace que el promedio en el FI se eleve de manera artificial en prejuicio de otras publicaciones; otro ejemplo sería una dependencia con pocas publicaciones y alto FI, con un promedio elevado que impactaría a su comunidad de manera negativa en la evaluación global de esa comunidad. Este último caso puede ejemplificarse con una de las dependencias del SIC que tiene el FI promedio más alto en el Subsistema: 4.9025. Este resultado tan alto se explica observando los artículos responsables del resultado. La dependencia en cuestión, publica diez artículos, uno en la revista Saienœe con un Factor de Impacto de 19.6070, un artículo en EarthandplanetarySCIlet. con 3.0320 deFI, tres artículos en Jour. Geophys. Res con 3.0260 de FI, un artículo en Meteoriticscon 2.5340 de FI, cuatro artículos en Geophysicscon 1.1616 de FI, y un artículo en Biología con 0.0500 de FI. La suma del FI de los seis títulos anterio res nos da un total de 29.415 y dividido entre esos seis títulos se obtiene un promedio de 4.9025 .

Tabla 10

\begin{tabular}{|c|c|}
\hline \multicolumn{2}{|c|}{ Factor de Impacto promedio } \\
\hline DEPENDENCIA & FI \\
\hline $\mathrm{Gq}$ & 4.9025 \\
\hline IBt & 3.7992 \\
\hline CIFN & 3.5359 \\
\hline IIB & 3.2273 \\
\hline $\mathrm{Gl}$ & 3.1339 \\
\hline IA & 3.0282 \\
\hline IFC & 3.0220 \\
\hline $\mathrm{CN}$ & 2.5846 \\
\hline Gf & 1.9644 \\
\hline IF & 1.6872 \\
\hline IQ & 1.6666 \\
\hline ICML & 1.4759 \\
\hline $\mathrm{ICN}$ & 1.4404 \\
\hline IIM & 1.3817 \\
\hline $\mathrm{CI}$ & 1.2967 \\
\hline $\mathrm{CCA}$ & 1.2723 \\
\hline $\mathrm{CE}$ & 1.2542 \\
\hline IIMAS & 1.2207 \\
\hline II & 0.9769 \\
\hline IB & 0.9692 \\
\hline IM & 0.5076 \\
\hline
\end{tabular}

Furte Curiala histónica de los investigadores J CR 1992. T8. 
Indicadores científicos: evaluaciones negativas proposiciones positivas 91

\section{A rtículos en revistas}

Al tener como fuente los currículos de los investigadores del SIC es posible observar que el primer trabajo fue publicado en 1938. El 0.11\% está localizado en la década de 1940 a 1949, un poco más del 1\% se encuentra localizado en la década de 1950 a 1959, el 5\% pertenece a la década comprendida entre 1960 y 1969, el 16\% corresponde a los años 1970 a 1979, el 47\% se sitúa entre 1980 a 1989 y el 30\% a los últimos cinco años estudiados de 1990 a 1994.

En una disposición tabular de los datos relativos al número de artículos por dependencia entre el total de artículos publicados en las 21 dependencias del Subsistema se encontró que el 50\% de los artículos, reportados por los investigadores en su curriculum, está concentrado en cinco dependencias: el 17\% en el IF , 10\% en el IB, 10\% en el IQ , 7\% en el IA y finalmente el 7\% en el IFC. Estas cinco dependencias son las que publican más artículos en el SIC.

Las cuatro dependencias con menor número de artículos publicados son:G I con el 1\%, G g con 1\%, CI con 1\% y CIFN con el 1\% (ver Gráfiø 9).

\section{Gráfico 9}

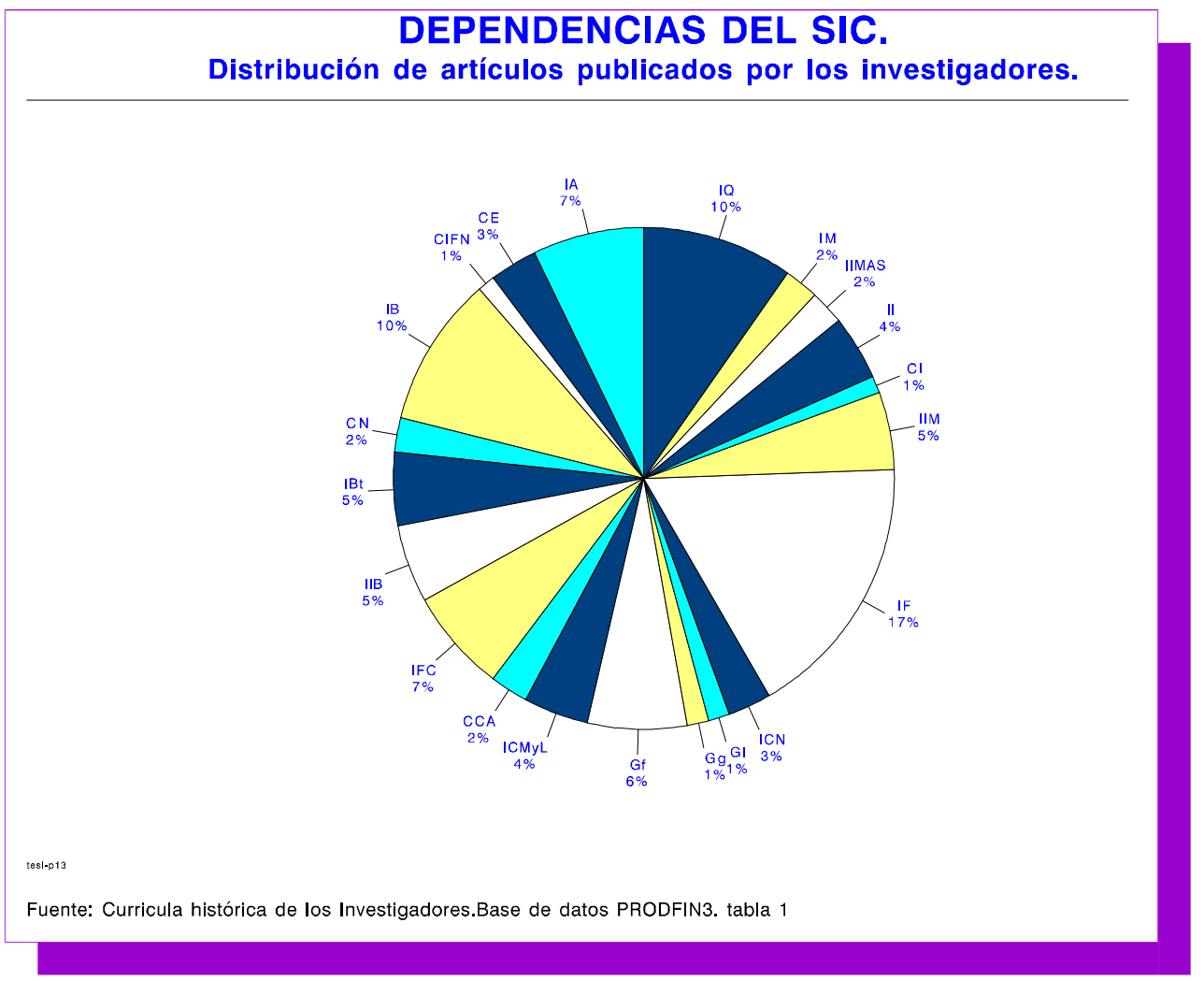


92 Investigadón Bibliotecológica v. 12 N o. 25 julio/ diciembre de 1998

Si concentramos la información en algunas áreas es posible observar que en la de Biología el mayor porcentaje de publicación le corresponde al IB con un 70\% y el menor al Centro de Investigación sobre Fijación de Nitrógeno con un 8\%, sin considerar el año de creación de cada dependencia.

En el área de Ciencias de la tierra, $\mathrm{G}$ f es el instituto que cuenta con un mayo $\mathrm{r}$ porcentaje de publicaciones, éste es del $40 \%$ y el instituto con menor productividad en esta área es $\mathrm{Gg}$ con un $8 \%$.

En el área Biomédica el mayor porcentaje le corresponde al IFC con un 36\% y el menor al CN . En el área de Física el 70\% es para el IF y el menor para el IC N con un $11 \%$.

En el área de Ingeniería el mayor porcentaje lo obtuvo el II con un 77\% y el menor el CI con $23 \%$.

En el área de Matemáticas el 53\% es para el IIMA S y el 47\% para el IM (ver Gráficos 10y 11).

Gráfico 10

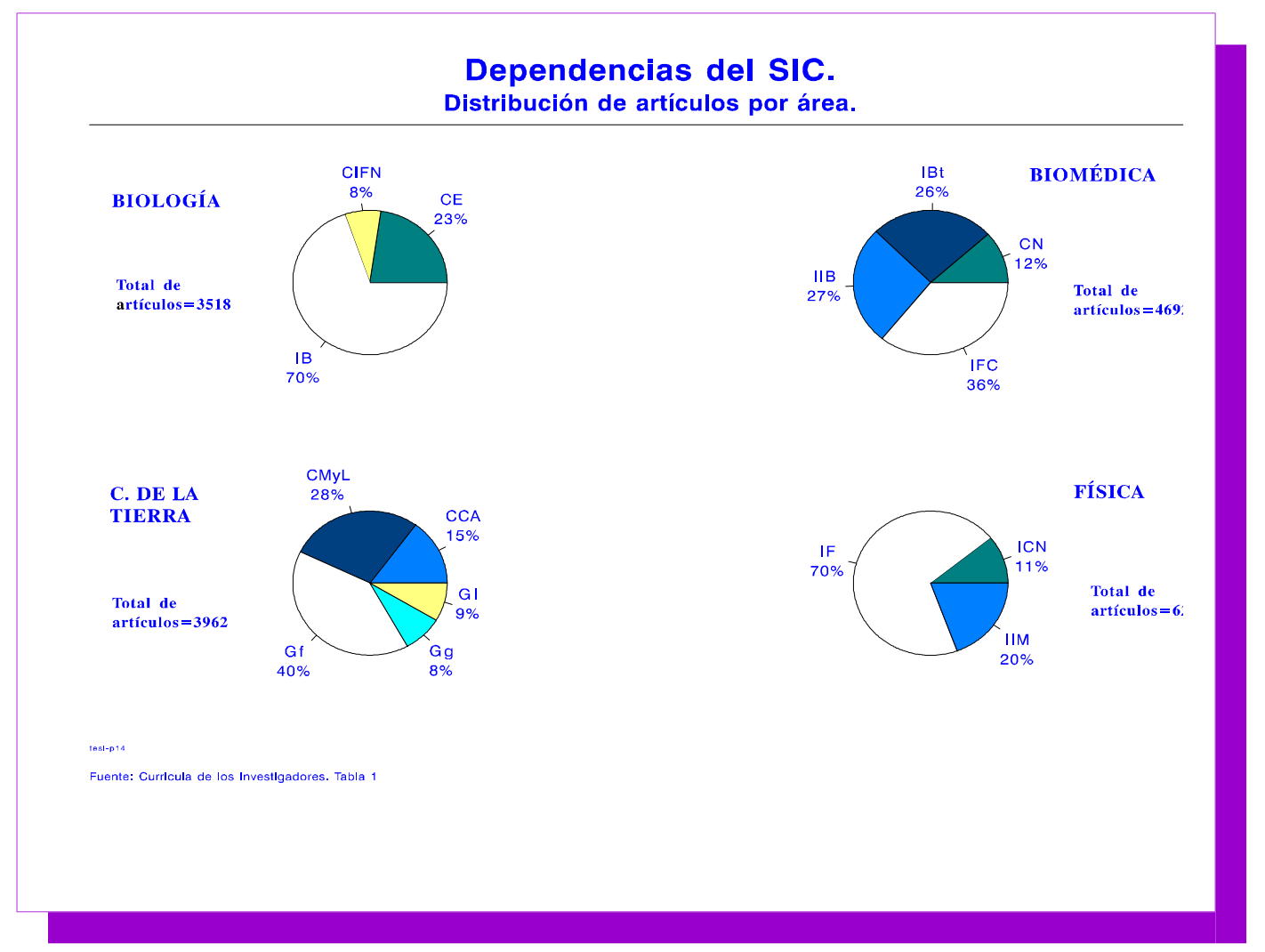


Gráfico 11

DEPENDENCIAS DEL SIC.

Distribución de artículos por área.

INGENIERÍA Y
TECNOLOGIA.

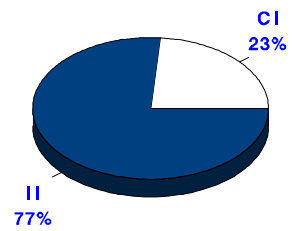

Totalde artículos $=1326$
MATEMÁTICAS.

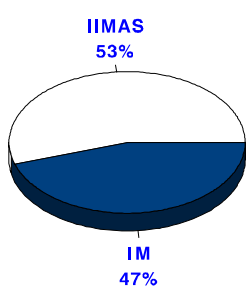

Totalde atículos $=1149$

Fuente: Curricula de los Investigadores. Histórico. tabla 1

D ividido por áreas, del total de artículos publicados, el 14\% corresponde al área de Biología, el 19\% a Biomédicas, el 16\% a Ciencias de la Tierra, el 25\% a Física, el 5\% a Ingeniería y el $15 \%$ a Matemáticas (ver Gráfico 12).

Al estudiar los artículos publicados por los investigadores en revistas, surge la pregunta sobre ¿cuál debe ser el número de artículos esperados anualmente por cada investigador? A ntes estos resultados se obtenían a partir del número de artículos reportados en índices comerciales, principalmente del SCI, sin embargo, aunque esta fuente es confiable, para otros datos sus limitaciones, ya señaladas, no sindican que los resultados quizá estén sesgados hacia las disciplinas con mayor representatividad.

Al analizar los datos tabulados contenidos en el conjunto formado por los artículos se puede inferir a partir de estos valores, que el comportamiento de las dependencias es diferente debido a que cada una tiene perfiles documentarios de las fuentes que maneja, que no deben limitarse a una cuantificación mecánica sin cuidar el contexto, por ese motivo no pueden ser evaluadas determinando un promedio global. 
94 Investigación Bibliotecológica v. 12 N o. 25 julio/ diciembre de 1998

\section{Gráfico 12}

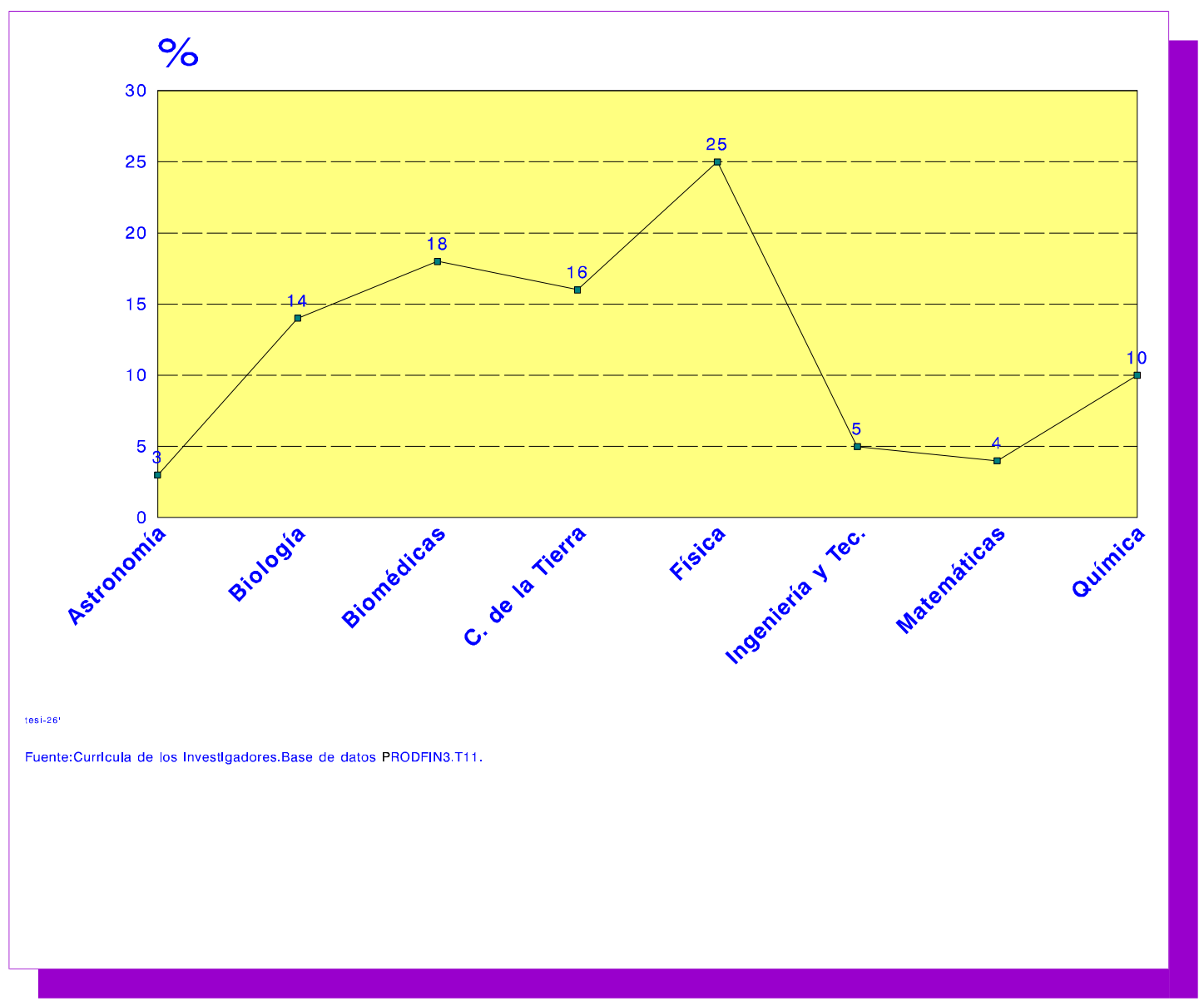

U tilizando los datos sobre la producción científica (artículos publicados en revistas) de los currículos de los investigadores y analizando los valores distintos observados durante los años 1980 a 1989 (la década completa, más actualizada) el promedio de artículo esperado en un año se muestra en la Tabla 11.

En síntesis la tabla muestra que los valores tabulados difieren en cada dependencia de acuerdo con las características de publicación de cada una de ellas y constituy en un escenario, que puede ser adecuado, para plantear, en principio, un criterio de apoyo para la evaluación. Estos criterios de evaluación pueden ser aplicables para obtener definitividad, promociones, contrataciones, premios tanto nacionales como internacionales, ingreso en asociaciones, pertenencia al Sistema Nacional de Investigadores (SIN), estímulos de productividad, participación en Colegios Invisibles, o para cualquier otro tipo de evaluación científica dentro y fuera de las instituciones. 
Indicadores científicos: evaluaciones negativas proposiciones positivas 95

Tabla 11

\begin{tabular}{|c|c|c|c|}
\hline \multicolumn{4}{|c|}{$\begin{array}{l}\text { Artículo por investigador en un año } \\
\text { (Años considerados } 1980 \text { - 1989) }\end{array}$} \\
\hline Áreas & Dependencias & $\begin{array}{l}\text { Artículo esperado } \\
\text { por D ependencia }\end{array}$ & $\begin{array}{l}\text { Artículo espe- } \\
\text { rado por área }\end{array}$ \\
\hline A stronomía & IA & 2.5 & 2.5 \\
\hline \multirow{3}{*}{ Biología } & $\mathrm{CE}$ & 0.99 & \\
\hline & CIFN & 0.68 & 1.52 \\
\hline & IB & 2.08 & \\
\hline \multirow{4}{*}{ Biomédica } & $\mathrm{CN}$ & 2.18 & \\
\hline & IBt & 1.22 & 1.47 \\
\hline & IIB & 1.27 & \\
\hline & IFC & 1.78 & \\
\hline \multirow{5}{*}{ C. de la Tierra } & $\mathrm{CCA}$ & 1.28 & \\
\hline & ICML & 0.91 & \\
\hline & IGf & 1.78 & 1.12 \\
\hline & $\mathrm{IGq}$ & 0.5 & \\
\hline & IGl & 0.81 & \\
\hline \multirow{3}{*}{ Física } & $\mathrm{ICN}$ & 2.28 & \\
\hline & IF & 2.76 & 2.06 \\
\hline & IIM & 1.01 & \\
\hline \multirow[t]{2}{*}{ Ingeniería y Tec. } & $\mathrm{CI}$ & 3.75 & 0.84 \\
\hline & II & 0.67 & \\
\hline \multirow[t]{2}{*}{ Matemáticas } & IIMAS & 0.59 & 0.51 \\
\hline & IM & 0.44 & \\
\hline Química & IQ & 2.49 & 2.49 \\
\hline
\end{tabular}

\section{Impacto de la obra publicada}

La cita es una mención que se hace a otros documentos relacionados con un trabajo, las citasindican influencia o impacto científico y siempre son posteriores al trabajo citado.

Una publicación puede ser citada por muchas razones:

* Rendir homenaje a los pioneros.

* D ar crédito a trabajos relacionados con el tema (homenaje a los pares).

* Identificar metodología, equipo etcétera.

* Proporcionar lecturas retrospectivas.

* Corregir el trabajo propio.

* Corregir el trabajo de otros.

* Criticar trabajos anteriores. 
96 Investigadón Bibliotecológica v. 12 N o. 25 julio/ diciembre de 1998

* Sustentar reclamaciones.

* Alertar sobre trabajos por venir.

* Dar protagonismo a trabajos pobremente diseminados, pobremente indizados, o no citados.

* A utentificar datosy clasificaciones de hechos -constantes Físicas etcétera.

* Identificar las publicaciones originales en las cuales una idea o un concepto fue probado.

* Identificar las publicaciones originales u otro trabajo que describa un concepto o término epónimo.

* Rechazar el trabajo o las ideas de otros. (D enuncia negativa)

- Disputar, al reclamar, las prioridades de otros (Homenajes negativos) (Weinstock, M. 1971).

Las citas reflejan el impacto que un trabajo pueda o no tener dentro del paradigma de la ciencia. Entendiéndose por paradigma el consenso que existe en una comunidad científica - partiendo de un marco conceptual establecido- sobre cuáles son los problemas interesantes, sus posibles soluciones y los métodos para abordarlos (Fortes, M. 1994).

Si el artículo recibe de 5 a 10 citas por año durante varios años después de su publicación, es casi seguro que su contenido llegará a formar parte del conocimiento, en su respectivo campo, pero si por el contrario no recibe citas durante los 5 a 10 años posteriores a su publicación, se puede afirmar que su contribución no será esencial para su disciplina dentro del paradigma contemporáneo de la ciencia (Brown, T., G länzel, W . y Schubert, A . 1985).

Según $\mathrm{G}$ arfield el 25\% de los artículos no son citados nunca, un $50 \%$ son citados una sola vez y un 1\% tienen 60 citas o más (Garfield, E. 1972).

La cantidad de citas bibliográficas que recibieron, hasta el año de 1994, los artículos publicados por los investigadores del SIC se obtuvieron mediante una búsqueda en el SCI, a partir de las referencias de los artículos publicados que se encuentran registrados en el curriculum histórico de cada investigador del subsistema. La búsqueda en el SCI con apoyo en el curriculum de cada investigador ofreció un resultado exhaustivo, ya que cuando las búsquedas para estudios comparativos se basan en la palabra clave "México" es posible que muchas citaciones se pierdan, o cuando por error de dedo los datos en el Science aparezcan distintos, la recuperación, sin tener el curriculum como apoyo, puede nuevamente perder citas.

En una disposición tabular de los datos relativos al número de citas por dependencia entre el total de citas obtenidas por los trabajos publicados en las 21 dependencias del Subsistema, se obtuvo un porcentaje de citas (ver Tabla12) en el que seencontró que el 48\% de las citas está concentrado en tres dependencias:

El IBt con un 19\%, el IF con un 16\% y el IFC con un 13\% (ver Gráfico13). 
Indicadores científicos: evaluaciones negativas proposiciones positivas 97

Tabla 12

\begin{tabular}{|c|c|}
\hline \multicolumn{2}{|c|}{$\begin{array}{c}\text { Porcentaje de citas del total en el SIC } \\
\quad \text { (Total de citas = 139 918) }\end{array}$} \\
\hline Dependencias & $\%$ de citas jeranquizadas \\
\hline IBt & 18.62 \\
\hline IF & 15.93 \\
\hline IFC & 13.19 \\
\hline IA & 11.42 \\
\hline IIB & 6.78 \\
\hline IQ & 6.77 \\
\hline $\mathrm{CN}$ & 3.55 \\
\hline CIFN & 3.08 \\
\hline $\mathrm{ICN}$ & 2.96 \\
\hline $\mathrm{Gf}$ & 2.86 \\
\hline $\mathrm{CE}$ & 2.71 \\
\hline IIM & 2.69 \\
\hline IB & 1.78 \\
\hline II & 1.67 \\
\hline $\mathrm{Gl}$ & 1.67 \\
\hline ICML & 1.56 \\
\hline IIMAS & 1.08 \\
\hline $\mathrm{CCA}$ & 0.61 \\
\hline $\mathrm{IM}$ & 0.58 \\
\hline $\mathrm{CI}$ & 0.35 \\
\hline $\mathrm{Gg}$ & 0.03 \\
\hline
\end{tabular}

Gráfico 13

DEPENDENCIAS DEL SIC.

Distribución de citas a trabajos publicados por los investigadores.

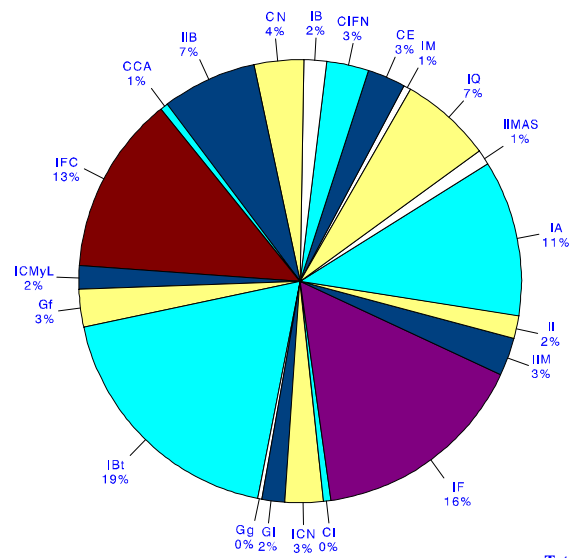

Total $=139918$ 
98 Investigación Bibliotecológica v. 12 N o. 25 julio/ diciembre de 1998

Garfield identifica temas de investigación de punta que están tocando problemas medulares, de actualidad científica extrema, y menciona que todo lo que estos temas generen será citado porque es la única literatura que se produce en esos campos.

El porcentaje correspondiente al número de citas por área muestra que de los 2 porcentajes más altos, el 42\% corresponde al área Biomédica y el 21\% al área de Física. El área de Ingeniería y T ecnológicas tiene un 2.03\% y la de Matemáticas un 1.67\%, que son los dos porcentajes más bajos (ver Gráfico14).

\section{Gráfico 14}

SIC. Distribución de citas a trabajos publicados por los investigadores. Por áreas.

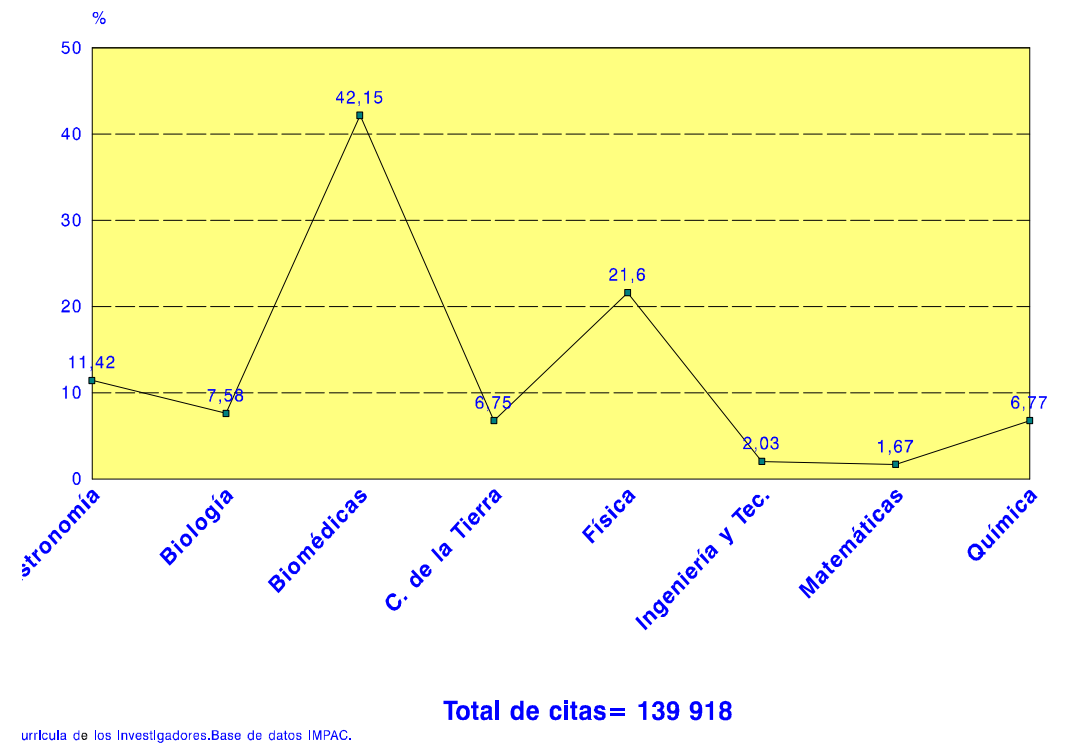

Al concentrar la información en algunas áreas es posible observar que en la de Biología el mayor porcentaje de citas le correspondeal C IFN con un $41 \%$, en Ciencias dela tierra con un $42 \%$ a G f, en el área Biomédica el mayor porcentaje le corresponde al Instituto de IBt con un 44\%, en el área de Física el 74\% es para el IF, en Ingeniería el 82\% es para el II y en Matemáticas el 65\% es para el IIMA S. (ver Gráficos 15y 16). 
Indicadores científicos: evaluaciones negativas proposiciones positivas 99

Gráfico 15

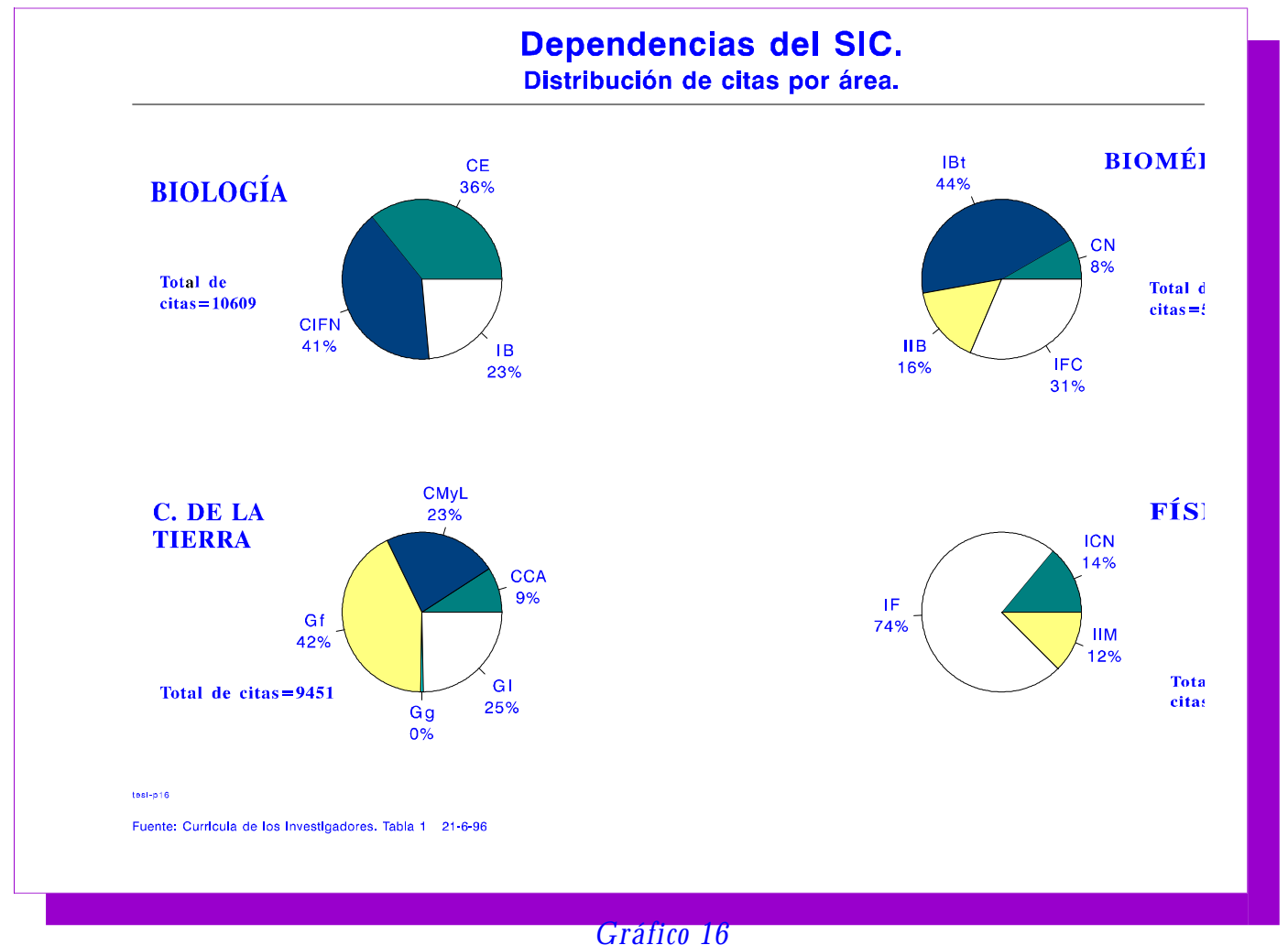

Gráfico 16

DEPENDENCIAS DEL SIC.

Distribución de citas por área.

INGENIERÍA Y
TECNOLOGIA.

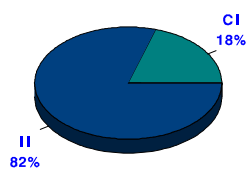

Total de citas $=2842$
MATEMÁTICAS.

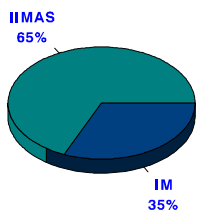

Total de citas $=2341$ 
En el siguiente gráfico se puede observar la distribución a partir de dos variables: la cantidad de citas obtenidas y la cantidad de artículos. La correlación entre los valores de las variables nos da un factor promedio por dependencia. El valor promedio calculado entre la cantidad de citas y la cantidad de artículos producidos se presenta en el siguiente gráfico en el que la cantidad de las fuentes de información en las que se publica el producto informativo generado por los investigadores del SIC, varía de acuerdo con el área temática de pertenencia (ver Gráfico 17).

Gráfico 17

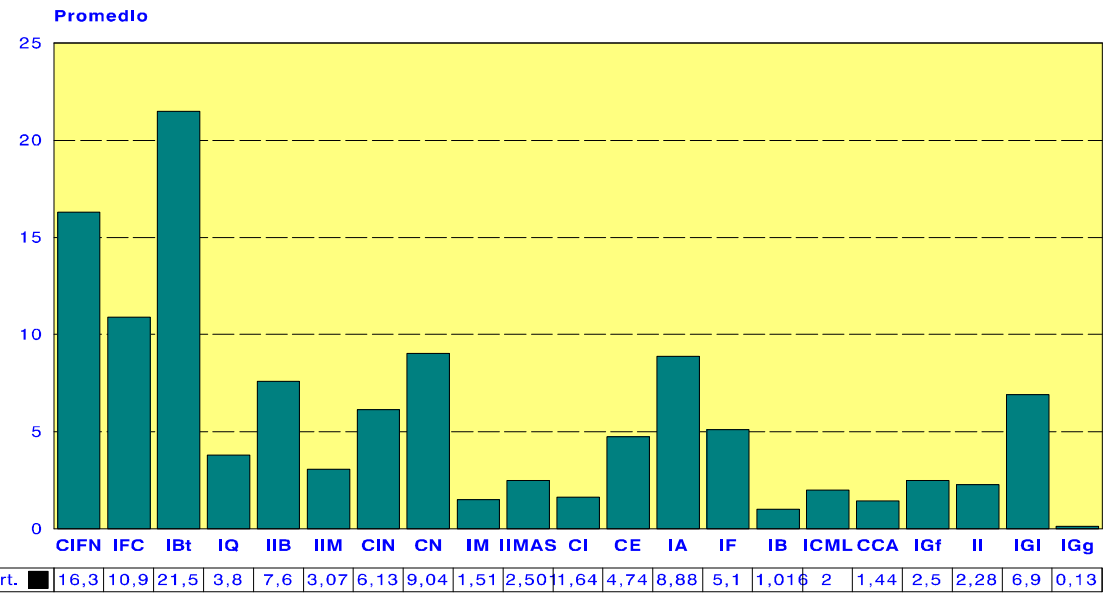

En la Tabla13se presenta el valor absoluto de citas recibidasy el valor promedio. El valor de "citas recibidas" se refiere únicamente a la cantidad de citas que recibió cada dependencia, sin embargo, el "valor promedio" es un indicador producto del resultado obtenido al calcular la cantidad de citas entre la cantidad de artículo s producidos, este valor puede ser utilizado como un indicador que junto con otros criterios sirva para evaluar la calidad de los artículos publicados.

En esa misma tabla es posible observar que la primera columna se encuentra jerarquizada en orden decreciente de acuerdo con el lugar que ocupa la dependencia por la cantidad de citas recibidas. En cuanto a la segunda columna que 
incluye la segunda variable, número de artículos, afecta el orden jerárquico inicial y así pueden observarse algunos movimientos en proporción a las citas recibidas y el número de artículos publicados.

Tabla 13

\begin{tabular}{|c|c|c|}
\hline \multicolumn{3}{|c|}{ Número de citas } \\
\hline Dependencias & $\begin{array}{l}\text { Lugar que ocupa } \\
\text { por núm. de citas }\end{array}$ & $\begin{array}{l}\text { Lugar que } \\
\text { ocupa por } \\
\text { valor } \\
\text { promedio.* }\end{array}$ \\
\hline IBt & 1 & 1 \\
\hline IF & 2 & 9 \\
\hline IFC & 3 & 3 \\
\hline IA & 4 & 5 \\
\hline IIB & 5 & 6 \\
\hline IQ & 6 & 11 \\
\hline $\mathrm{CN}$ & 7 & 4 \\
\hline CIFN & 8 & 2 \\
\hline ICN & 9 & 8 \\
\hline $\mathrm{Gf}$ & 10 & 13 \\
\hline $\mathrm{CE}$ & 11 & 10 \\
\hline IIM & 12 & 12 \\
\hline IB & 13 & 20 \\
\hline II & 14 & 15 \\
\hline $\mathrm{Gl}$ & 15 & 7 \\
\hline ICML & 16 & 16 \\
\hline IIMAS & 17 & 14 \\
\hline $\mathrm{CCA}$ & 18 & 19 \\
\hline IM & 19 & 18 \\
\hline CI & 20 & 17 \\
\hline $\mathrm{Gg}$ & 21 & 21 \\
\hline
\end{tabular}

* Luger que ocapa la dependencia de acuerdo al porcentaje obterido etree númæro decitas y e númoro de atíalos

El número de citas recibido por las dependencias no siempre corresponde en calidad con el número de artículos publicados. El 24\% guardó una proporción igual al número de citas y número de citas entre artículos, el 38\% bajó y 38\% subió.

A fin de calcular el "Promedio por área" de citas para todo el Subsistema se correlacionaron igualmente dos variables: citas y artículos publicados. Se analizaron seis áreas. El promedio por área refleja el número de artículos publicados entre el número de citas recibidas, teniendo como fuente el curriculum histórico de cada investigador y sumando los resultados por dependencia y posteriormente por área. 
Gráfico 18

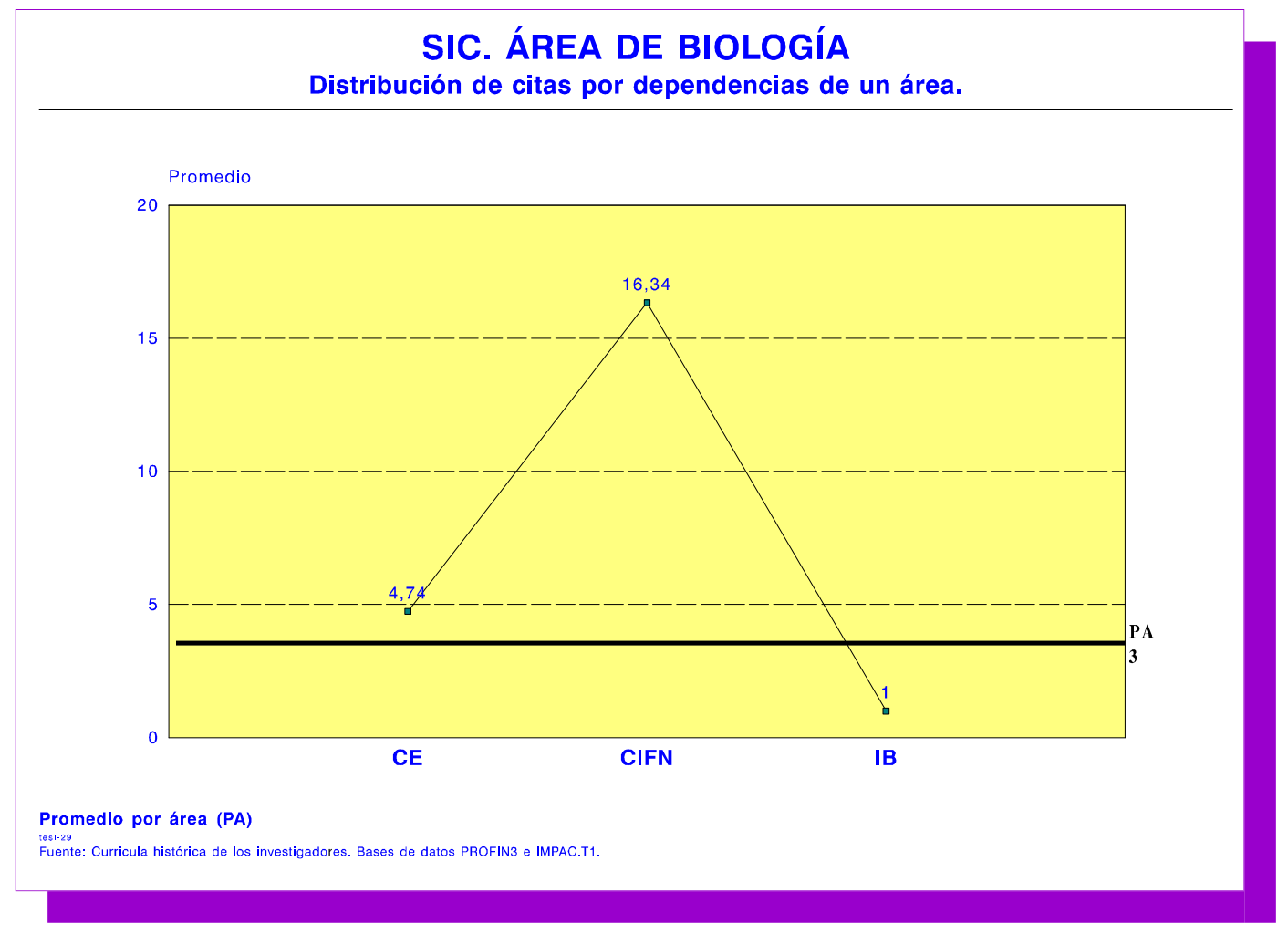

Entre las tres dependencias que la conforman, en el área de Biología el promedio de citas recibidas por trabajo publicado es de tres (ver Gráfico 18). En este grupo el porcentaje de citas recibidas es de $41 \%$ para el CIFN , de 36\% para el CE y del 23\% para el IB. En cuanto a los porcentajes de artículos publicados el CIFN tiene un 8\%, el CE un 23\% y el IB un 70\% (ver Gráfico 19).

En el área Biomédica el promedio de citas recibidas por trabajo publicado es de 12.5. Esta área está formada por cuatro dependencias, mientras que tres de ellas conservan un promedio semejante, el promedio del IBt es significativamente mayor respecto a las otras dependencias que conforman el área, por consiguiente, al igual que en el área de Biología, nuevamente una sola dependencia, en este caso Biotecnología, influye en el promedio obtenido de citas recibidas por trabajos publicados. El porcentaje de citas obtenidas por dependencia respecto al to tal en esta área es el siguiente: para el C N un 8\%, para el IBt 44\%, para el IIB un $16 \%$ y para el IFC un 31\%, mientras que el porcentaje de trabajos es del $12 \%$ para el C N , del 26\% para el IBt, del 27\% para el IIB y del 36\% para el IFC. 
Indicadores científicos: evaluaciones negativas proposiciones positivas 103

Gráfico 19

\section{SIC.ÁREA BIOMÉDICA.}

Distribución de citas por dependencias en un área.

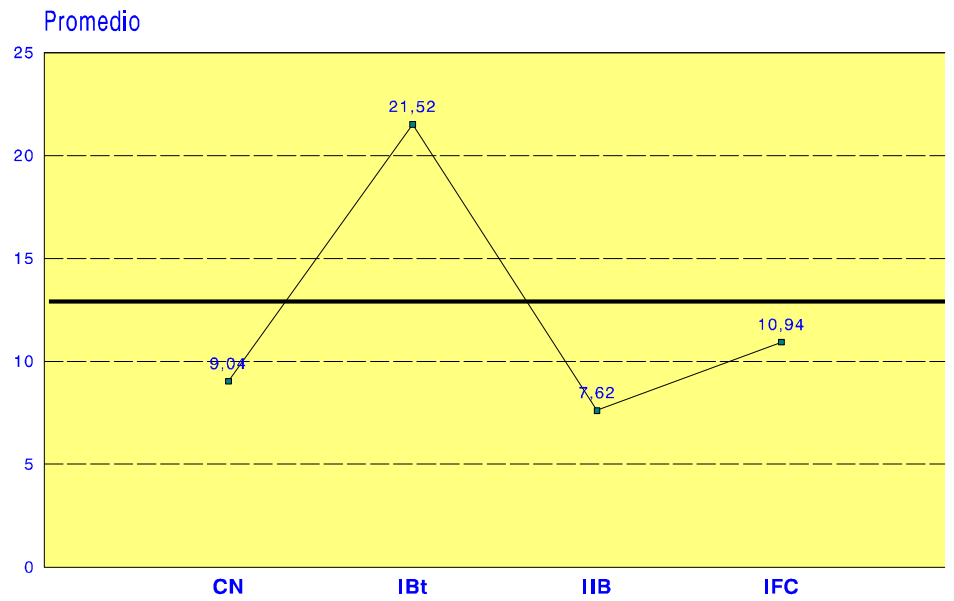

Promedio por área (PA).Número de citas/ núm. de artículos.

tos:-30
Fuente: Curricula historica de los investigadores. Bases de datos PROFIN3 e IMPAC

Gráfico 20

SIC. ÁREA DE CIENCIAS DE LA TIERRA

Distribución de citas por dependencias en un área.

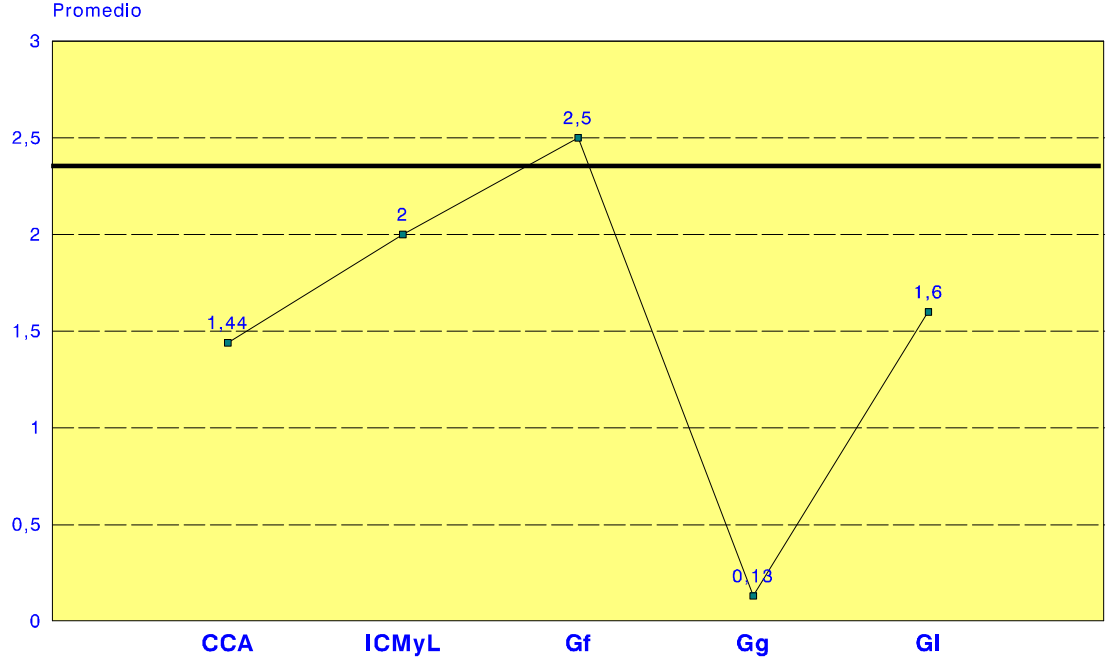

Promedio por área (PA) Número de citas / núm. de artículos.

Fuente: Curricula historica de los investigadores. Bases de datos PROFIN3 e IMPAC. 
104 Investigación Bibliotecológica V. 12 N o. 25 julio/ diciembre de 1998

El área de Ciencias de la Tierra (ver Gráfico20) está constituida por cinco dependencias, cuatro institutosy un centro, mismos que han obtenido un promedio de 2.3 citas por trabajo. Mientras tres dependencias conservan un promedio entre el 1.4 y 2, otra dependencia baja de manera significativa y la última dependencia parece alterar la muestra con un sesgo. El hecho de que dentro de las dependencias analizadas $\mathrm{Gl}$ hay a obtenido un porcentaje alto de citas reales, tiene que ver con la relación entre artículos producidos y citas recibidas.

En este instituto el porcentaje fue de 1.6, un porcentaje que si se relaciona por ejemplo con $\mathrm{G} g$ parece muy alto, pero esto se debe a que Gl tiene pocos artículos y pocas citas recibidas que al promediarlas producen un resultado alto, lo que hace aparecer la muestra como viciada o que altera a las demás dependencias.

El porcentaje de citas recibidas en el área de $\mathrm{C}$ iencias de la Tierra por cada una de las dependencias que la conforman es del $9 \%$ para CCA, del $23 \%$ para ICMyL, del 42\% para Gf, del 0.48\% para Ggy del 25\% para Gl. En cuanto al porcentaje de artículos publicados el 15\% es del C CA , el 28\% del IC MyL, el 40\% de Gf, el $8 \%$ de Ggy el $9 \%$ de Gl.

Gráfiø 21

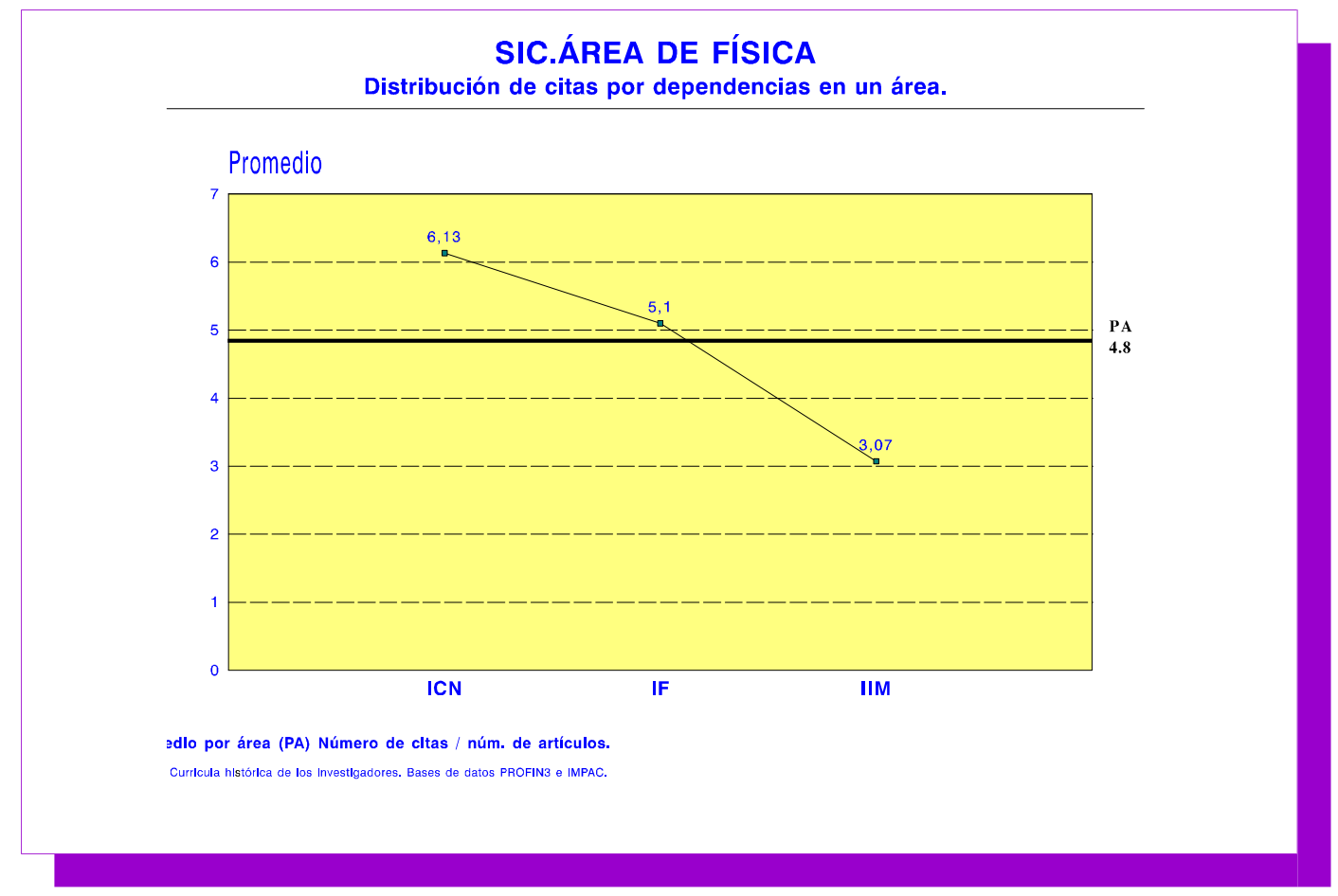

El área de Física (ver Gráfiø21) está constituida por tres institutos. Mientras el ICN tiene un promedio alto de citas recibidas en esta distribución, el IF 
tiene una posición intermedia y el IIM un promedio más bajo, lo que da, para esta área, un promedio de citas por trabajo de 4.8.

El porcentaje de citas por dependencia en esta área es de $14 \%$ para el IC N , de $74 \%$ para el IF y del $12 \%$ para el IIM. En cuanto al porcentaje de trabajos publicados por estas dependencias es del 11\% para el ICN , del 70\% para el IF y del $20 \%$ para el IIM.

Gráfico 22

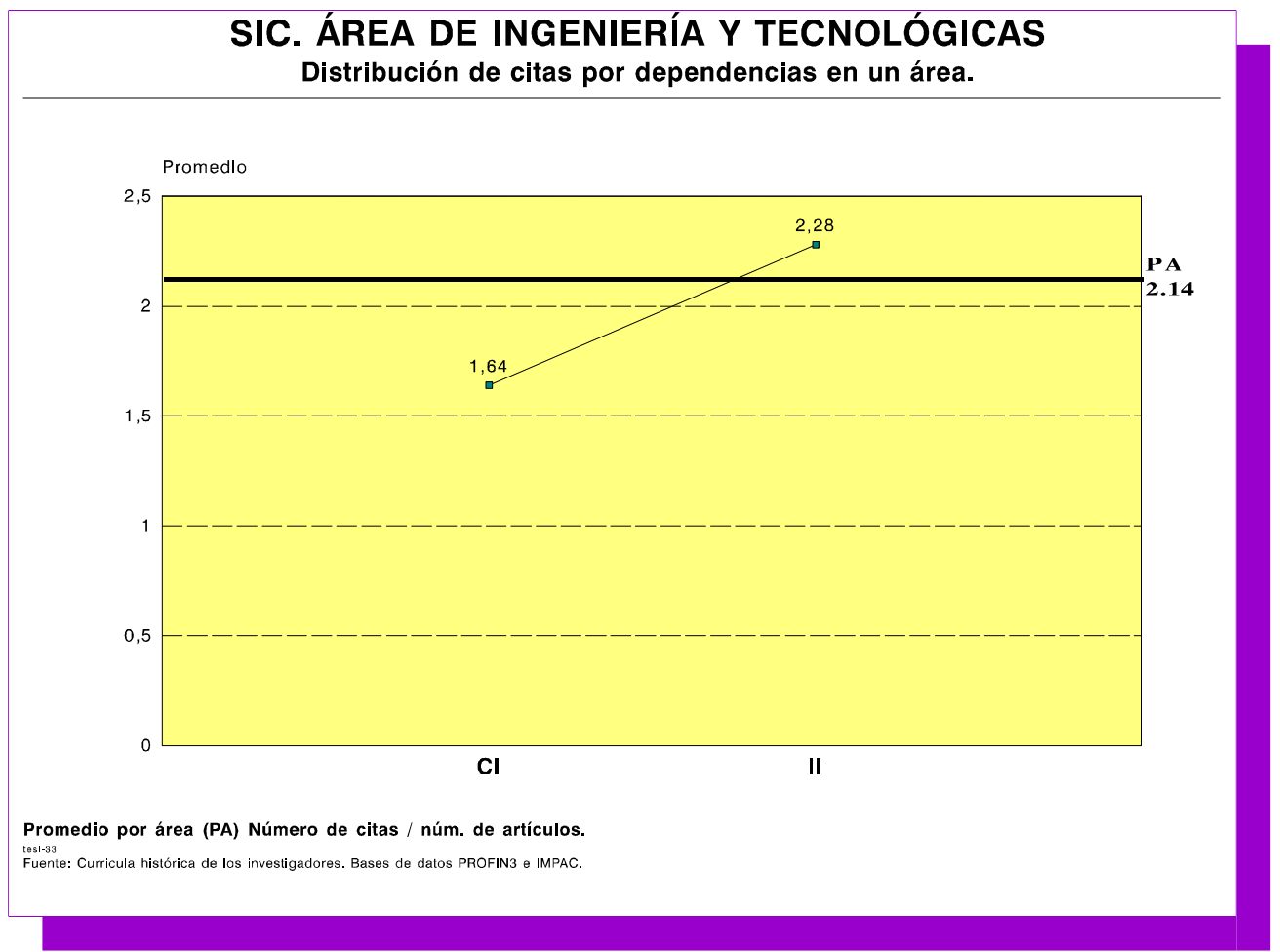

En el área de Ingeniería y T ecnológicas el promedio de acuerdo con la información proporcionada por los investigadores en su curriculum es de 2.14 citas recibidas para cada trabajo publicado. Esta área está constituida por dos dependencias que son CI y el II, su relación en cuanto a porcentajes no está polarizada como en otras dependencias analizadas por área. El porcentaje de citas por dependencia en esta área es de 18\% para C I, y del 82\% para el II. El porcentaje de trabajos publicados es de $23 \%$ para el CI y de $77 \%$ para el II.

En el área de matemáticas se encuentran dos dependencias cuyos resultados en el porcentaje de citas oscila entre el 2.5 y el 1.5. En estaárea del SIC el promedio es de 2 citas por cada artículo publicado. El porcentaje de citas recibidas por trabajo publicado en esta área el 65\% es para el IIMA Sy el 35\% es para el IM.En 
106 Investigación Bibliotecológica v. 12 N o. 25 julio/ diciembre de 1998

cuanto al porcentaje de artículos publicados es de 53\% para el IIMA S, y de 47\% para el IM.

Gráfico 23

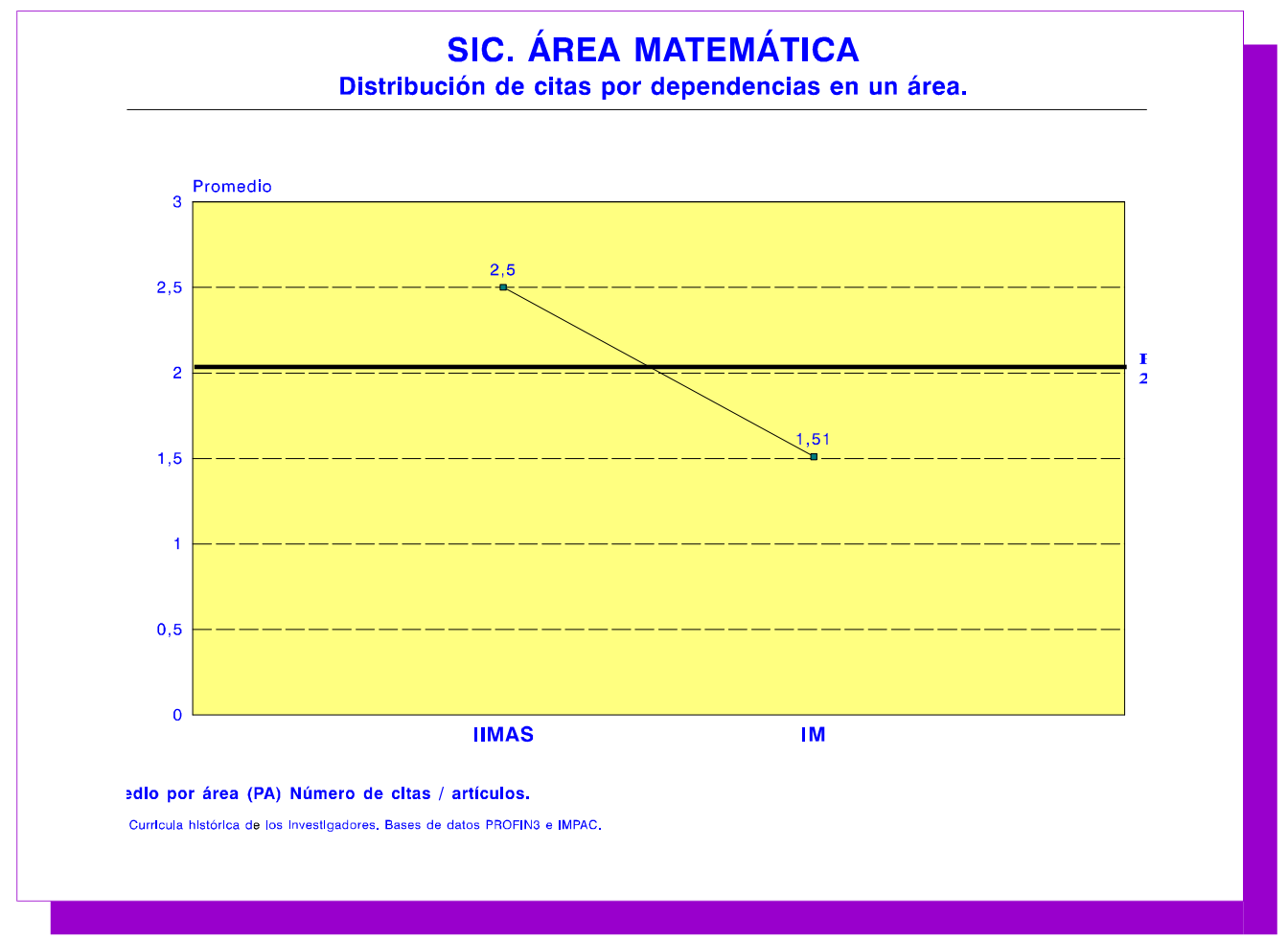

\section{CONSIDERACIONES GENERALES}

* El conocimiento sobre el comportamiento de las regularidades de la producción científica, de una institución o sistema científico, coadyuva a la toma de decisiones en materia de política científica sobre bases más objetivas.

* El bajo porcentaje de inversión que nuestro país aplica a la ciencia y la tecnología posiblemente tiene como origen el que la actividad científica profesional en nuestro país es joven, ya que por ejemplo en la UNAM sólo 3 institutos -aunque con antecedentes- se fundaron en 1929, dos en 1938, cuatro en los años cuarenta, tres en los años setenta y cuatro en los años ochenta.

- O tra razón para explicar los bajos recursos asignados ala actividad científica es que ésta ha dado pocos frutos visibles para la sociedad, por consiguiente el gobierno no tiene la demanda de los mexicanos para que se le impulse. 
Indicadores científicos: evaluaciones negativas proposiciones positivas 107

* La investigación que se lleva a cabo en la Universidad Nacional Autónoma de México (UNA M) tiene un alto reconocimiento tanto en el ámbito nacional como en el internacional.

* En México el mayor número de personas con doctorados nacionales es egresado de la UNAM.

* La UNAM es la institución con mayor número de "Investigadores Nacionales".

- Los estudios comparativos de productividad e impacto desarrollados por otros países, en el área de ciencias naturales y exactas, en la esfera mundial utilizan por lo general como fuente el Saience Citation Index (SCI).

* Según el SCI en un 79\% la revista científica es el tipo de documento en donde más publican losinvestigadores mexicanos en el área deciencias.

* Si la Universidad Nacional se compara con las 5 instituciones nacionales más productivas, la UNA M obtiene un $54 \%$ de la producción, seguida por el CINVESTAV con un 17\%, el Sistema SEP/CO NACyT con $12 \%$, la UAM con un $10 \%$, el IPN con un $4 \%$, y el ININ con un $3 \%$.

* Si la UNA M se compara con la institución inmediata, jerarquizada en orden decreciente, es decir el CINVESTAV, la UNA M obtiene un $68 \%$ de esa producción.

* Respecto a la UNA M el SIC representa el 70\%, por lo tanto el producto informativo generado por los investigadores del Subsistema puede ser considerado como la mayor aportación que se genera en el país en el campo de la investigación científica.

* A fin de que los estudios comparativos para nuestro país no continúen basándose únicamente en bancos de información comerciales que tienen un gran sesgo, pero que son la única fuente de consulta para este tipo de estudios, se recomienda que cada instancia en donde se lleve a cabo investigación cuente con bases como las desarrolladas en la Unidad de Indicadores de Productividad Científica de la UN A M, creada en 1991, con la misma normalización y perfil para formar una red nacional avalada que dé peso a nuestra investigación en el ámbito internacional.

- Los investigadores del SIC tienen un alto nivel académico, ya que el 67\% son titulares.

* La existencia de un sistema de fuentes de información propia permite el diseño y evaluación de indicadores científicos sobre bases objetivas.

* Los currículos de los investigadores constituyen una valiosa fuente para la evaluación de su producción científica, puesto que ofrecen una información validada, objetiva y confiable.

* Si se contempla un total global en el Subsistema de la Investigación Científica, el documento con mayor representatividad esla revista científica, ya que el 71 por ciento delas dependencias publica más en revistas 
que en cualquier otro documento, y el 29 por ciento publica menos en revistas y más en otro tipo de documento, sin que esto signifique que la revista esté excluida en alguna de las disciplinas del subsistema.

* El 36\% del total de títulos en donde publican los investigadores del SIC tienFI, mientras que el 63\% no cuenta con este reconocimiento.

* No existe una correspondencia entre las dependencias que publican en un mayor número de títulos de revistas y un alto FI.

* Las dependencias con porcentaje más bajo en el FI son aquéllas en las que su principal fuente de publicación no es la revista.

- La cantidad e impacto de los artículos en los que se publica el producto informativo generado por los investigadores del SIC, varía de acuerdo con el área temática de pertenencia.

- Las revistas científicas mediante las cuales se difunde el producto informativo generado por los investigadores del SIC tiene diversos matices, pero en un muy alto porcentaje reflejan impacto y prestigio profesional en la comunidad científica internacional.

* Las dependencias que muestran una mayo r dispersión en sus títulos son 7 y en ellas aparece más del $50 \%$ de los títulos repetidos.

* Las dependencias con menor dispersión en el número de títulos elegidos para publicar son cinco.

* Por áreas es Física la que publica en un mayor número de títulos de revistas, mientras que matemáticas es la que concentra su información en un menor número de títulos.

* El FI por sí solo no determina la calidad de una revista en donde publica un investigador, ya que ésta debe estar asociada entre otras al prestigio, al área temática, al contenido etcétera.

* D e los 3701 títulos de revistas analizados sólo 2040 títulos tuvieron FI en el JCR - ed. 1992 -, sin embargo, aunque los 1661 títulos que no obtuvieron FI no aparezcan en el JCR es posible analizarlos en un trabajo posterior para obtener su FI correspondiente.

* El promedio de las revistas con FI en el subsistema es de 35\%.

- Las tres dependencias con el promedio más alto en la relación entre el total de títulos de revistasy el número de revistas con FI son CIFN , IBt, IFC.

* La mediana como medida de tendencia central muestra ante datos extremos un FI menos sensible.

- Al aplicar la mediana a las dependencias se encontró que una dependencia obtuvo más de 3 puntos en su FI, tres dependencias más de 2, diez dependencias más de 1 y siete dependencias menos de uno.

* La mayoría de dependencias que aplican la mediana se encuentra en el grupo que obtuvo entre 1.9630 y 1.0510 de FI. 
Indicadores científicos: evaluaciones negativas proposiciones positivas 109

* El FI más elevado por dependencia en el SIC fue de 37.1600 para 3 dependencias, de 20 para una, de 19.60 para trece, de 19.33 para 5, y menor de 8 para cuatro dependencias.

* El FI promedio por dependencia aumenta respecto a la mediana, alrededor de un $48 \%$ aproximadamente.

* A plicando el promedio, el resultado que obtiene una dependencia es sensible ante datos extremos, ya que se eleva de manera artificial en prejuicio del total de los investigadores en la evaluación glo bal de su comunidad.

* El 50\% del total de artículos publicados se concentra en 5 dependencias del subsistema, éstas son el IF, IB, IQ , IA, IFC.

* Las dependencias que publican un menor número de artículos son: Gl, Gg, CI, CIFC.

* Por áreas las que tienen mayor número de artículos publicados son: en Biología, el IB; en Ciencias de la tierra, el IG f; en Biomédicas, el IFC; en Física, el IF; en Ingeniería, el II; en Matemáticas, el IIMA S.

* Por áreas los porcentajes de artículos publicados son: un 14\% de Biología, el 19\% de Biomédicas, el 16\% de Ciencias dela tierra, el 25\% de Física, el 5\% de Ingeniería, y el 15\% de Matemáticas.

* El número de artículos esperados, por año, por autor no debe obtenerse de fuentes externas sino de los propios datos.

* El artículo por investigador por año para el IA es de 2.5, para el CE es de 0.99, para el CIFN es de 0.68, para el IB de 2.08, para el CN de 2.18, para el IBt de 1.22, para el IIB de1.27, para el IFC de 1.78, para el C CA de 1.28, para el ICML de 0.91, para el IGf de 1.78, para el IG g de 0.5, para el IGl de 0.81, para el IC N el 2.28, para el IF el 2.76, para el IIM el 1.01, para el C I el 3.75, para el II el 0.67, para el IIMA S el 0.59, para el IM el 0.44, para el IQ el 2.49 .

* El 48\% de las citas recibidas a los trabajos publicados está concentrado en tres dependencias: IBt, IF, y el IFC.

* Por áreas el porcentaje de citas más alto corresponde al área Biomédica.

* Por áreas el porcentaje más alto de citas obtenidas en Biología corresponde al C IFN , en Ciencias de la Tierra a G f, en el área Biomédica al IBt, en Física al IF, en Ingeniería al II, en Matemáticas al IIMA S.

* La frecuencia con que un artículo es citado por dependencia es para IBt 21, para CIFN 16, para IFC 11, para CN 9, para IA 9, para IIB 8, para IGl 7, para CIN 6, para CE 5, para IF 5, para IQ 4, para IIM 3, para CI 2, para IG 2 , para II 2, para ICML 2, para IIMA S2, para IB 1, para CC A 1, para IM 1, para IG g 0.13 .

* El número de citas recibido por las dependencias no siempre corresponde al número de artículos publicados. El 24\% guardó una proporción igual al número de citas y número de citas entre artículos, el 38\% bajó y $38 \%$ subió. 
* Entre las tres dependencias que conforman el área de Biología, el promedio de citas recibidas por trabajo publicado es de tres. En este grupo el porcentaje de citas recibidas es de $41 \%$ para el CIFN, de 36\% para el CE y del 23\% para el IB. En cuanto a los porcentajes de artículos publicados el CIFN tiene un 8\%, el CE un 23\% y el IB un $70 \%$.

* En el área Biomédica el promedio de citas recibidas por trabajo publicado es de 12.5. El porcentaje de citas obtenidas por dependencia respecto al total en esta área es el siguiente: para el CN un 8\%, para el IBt 44\%, para el IIB un $16 \%$ y para el IFC un $31 \%$; mientras que el porcentaje de trabajos es del $12 \%$ para el CN , del $26 \%$ para el IBt, del 27\% para el IIB y del $36 \%$ para el IFC.

* El área de Ciencias de la Tierra está constituida por dependencias, que han obtenido un promedio de 2.3 citas por trabajo. El porcentaje de citas recibidas en el área de $C$ iencias de la Tierra por cada una de las dependencias que la conforman es del $9 \%$ para C CA, del 23\% para IC MyL, del $42 \%$ para Gf, del $0.48 \%$ para G gy del $25 \%$ para G l. En cuanto al porcentaje de artículos publicados el 15\% es del CCA, el 28\% del ICMyL, el 40\% de Gf, el 8\% de Gg y el 9\% de Gl.

* El área de Física está constituida por tresinstitutos con un promedio de 4.8. citas por trabajo publicado. El porcentaje de citas por dependencia en esta área es de 14\% para el ICN , de 74\% para el IF y del 12\% para el IIM. En cuanto al porcentaje de trabajos publicados por estas dependencias es del 11\% para el IC N, del 70\% para el IF y del 20\% para el IIM.

* En el área de Ingeniería y T ecnológicas el promedio es de 2.14 citas recibidas para cada trabajo publicado. El porcentaje de citas por dependencia en esta área es de 18\% para C I, y del 82\% para el II. El porcentaje de trabajos publicados es de 23\% para el CI y de 77\% para el II.

* En el área de Matemáticas el promedio es de 2 citas por cada trabajo publicado. El porcentaje de citas recibidas por trabajo publicado en esta área es del 65\% para el IIMA Sy del 35\% para el IM. En cuanto al porcentaje de artículos publicados es de 53\% para el IIMAS, y de 47\% para el IM.

* A fin de que el resultado para obtener el promedio tanto de trabajos como de citas se ajuste aún más a la muestra, se recomienda analizar cada una de las dependencias del SIC por departamento, subdisciplina 0 por tópico de estudio. 
Indicadores científicos: evaluaciones negativas proposiciones positivas 111

\section{BIBLIOGRAFÍA}

A mat, N . (1979)- Ténicasdoaumentalesy fuentesdeinformadón. Barcelona : BIBLIO GRAF. pp 485.

Aversa, E. (1992)- Addingvaluetolibrary serviœes with ditations Conferencia: Las revistas científicas México D . F. UNA M 22-23 septiembre p. 12. (Separata)

Bowker (1992)- Ulrich's international periodicals directory 1992-1993 : including irregular serials and annuals. - 31st. ed. - N ew providence : Bowker. 3v.

Brown T., W. G länzel, A. Schubert. (c1985)- Saientometricindicators: A 32-Country comparativeevaluation of publishing performanœeand atation impact. Singapore : World Scientific . pp 424.

Chalmers, A . (1982)- ¿Qué es una cosa llamada dendia? Madrid : Siglo XXI, pp 120

Diodato, V. (c1994)- Dictionary of Bibliometrics New Y ork : The Haworth Press. pp 185.

EBSCO (1992)- The Serials Directory. EBSCO CD-RO M. Birmingam : EBSC O Publishing,

Esteva, L. (1990)- "Las áreas de Ciencias de la Tierra e Ingeniería: diagnóstico y perspectivas." Reunión Foránea del CTIC. Jurica, Q uerétaro, Q ro. pp 1- 8, 1-4 agosto.

Ferrater M. J. (1975.)- Diocionario de Filosofía. Editorial Sudamérica : Buenos A ires. 2 vol. pp 2080.

Ferreiro, L. (1993)- Bibliometría : análisisbivariante Madrid : EY PASA. pp 480.

Fey erabend, P. (1981)- Contra el método. Barcelona : A riel, pp 208.

Fortes M. (1994)- Investigación básica y desarrollo tecnológico. Co ngreso E milio Rosenblueth, Los futuros de la ingeniería en México. México D. F., pp 9. (Separata)

$\mathrm{G}$ arfield E. (1979)- Citation indexing: itstheory and applicationsin saienœ, technology and Humanities N ew Y ork : Jo hn Wiley \& Sons.

- -. (1972)- "Citation analy sis as a tool in a journal evaluation." Scienœ. $178: 471-479$.

- -. (1979)- Citation Indexin. N ew Y ork : Wiley and Sons.

- -. (1983)- "How to use citation analy sis for Faculty Evaluations, and when is it relevant?" Part 2. Current Contents 45 :5-13.

G orbea, S. (1994)- "Principios teóricos y metodológicos de los estudios métricos de la información." Investigación Bibliotecológica: archivonomía, biblioteoología einformadón. 8 (17) :23-32. 
112 Investigación Bibliotecológica v. 12 N o. 25 julio/ diciembre de 1998

G orbea, S. (1997)-El modelomatemáticodeBradford: suaplicadón a lasrevistaslatinoamericanas delasciencias bibliotecológicaydelainformación. México : C U IB-UNA M. pp 152.

G ross, P. y , E. G ross (1927)- "College Libraries and Chemical Education." Science 28 (66): :578-596

Internet(1997)-(http:// www.isinet.com/ aboutisi.html) p3.

ISI. (c1995)- "Science Citation Index 1994." Annual : Guide and list of sourcepublications: Philadelphia : ISI pp 150.

Journal Citation Reports : (1992)- A bibliametric analysis of sciencejournalsin theISI database, 1991. Science Citation Index. Philadelphia : ISI, pp 111.

K uhn, T. (1971)- La estructura delas revoludiones dientíficas México : Fondo de Cultura Económica.

López Piñero J.M. y M.L. Terrada. (1992)- Los indicadores bibliométricosy la evaluación de la actividad médico-científica. 1V. La aplicación de los indicadores. Med Clin. 98. 384-388.

Mijailov, A . (1973)- Fundamentosdelainformática. Moscú- La Habana : IDICT-A CC. 2V, pp 716.

Moed, H . (1988)- Theuse of On-linedatabases of bibliometrics analysis A msterdam : Elsevier SciencePublishers. pp 120.

Morales M. (1988)- Introducción a la informetría. A nálisis de los flujos informacionales y evaluación de las fuentes de información. La Habana, pp 24.

Moravcsick, M.J. (1989)- “¿Cómo evaluar la ciencia y a los científicos?” Revista Española de doaumentadoón dentífica 12 (3) :313-325.

N arin F. (1976)- Evaluativebibliometrics: The use of publication and citation analysisin theevaluation of scientificadivity. N ew Jersey : Computer Horizons, Inc. pp 319.

O CD E, (1987)- Repart 1986. París : O CDE.

- -. (1995?)- La OCDE en pocas palabras pp 18.

- -. (1989)- Themeasurement of scientific and tedhnical adtivities "Frascati Manual" París : O CD E. pp 73.

Price D. de Solla, D. (1963)- Little science, big science N ew Y ork : Columbia University Press. pp 182.

- - . (1963)- SaiencesinœBabylon. N ew Haven : Y ale University Press. pp 176.

- -. (1965)- Networks of scientific papers. Saienc. 149 : 510515. 
Indicadores científicos: evaluaciones negativas proposiciones positivas 113

Price, D . de Solla. (1986)-.Little science, big science.. and beyond. New Y ork : Columbia University Press. pp 301.

Pritchard A . (1969)- "Statistical bibliography on bibliometrics." Journal of doamentation. 25 (4) :348-349.

Sancho, R. (1990)- "Indicadores bibliométricos utilizados en la evaluación de la cienciay la tecnología." Revisión bibliográfica. RevistaEspañola dedoaumentadón científica 13 (3-4) :842-865.

Sancho, R. (1988)- Indicadores científicos para la evaluación de la ciencia y tecnología en los países en vías de desarrollo. Ađt.Inf.Cient.Témica. 140 (3) :19-69.

Saracevic, T y J. Wood (1981)- Consolidadión dela informacón, manual deevaluadón, røstructuracón y modificación deal informacón científica y técnica. Publicación preliminar. París : UN ESC 0 , pp 327.

Sen B., A., U. Karanjai, A. Munshi. (1989)- Method for determining the impact factor of a non-SC I journal. Journal of doaumentation. 45 (4) :139-141.

Spinak, E. (1996)- Diocionario Encidopédico dela Bibliometría, Cienciometría, eInformetría. Caracas : UNESC O . pp 245.

UNA M. ( 1992)- Informe México : UNAM. 2 V pp 638.

- -. (1987 )- Legidación Universitaria. Estatuto del personal académico de la Universidad Nacional Autónoma de Méxio. México : UNA M. pp 224.

- -. (1988)- Coordinación dela Investigación Científica : Institutosy CentrosdeInvestigación Científica. - México D .F. : UNA M, CIC. 23 p.

- -. (1995)- Memoria 1995. México : UNA M. pp 1008.

UNESC O . (1965)- Saientific and technical doamentation centers París : UNESC O, pp 120.

Weinstock, M. (1971)- Citation indexes, Encyclopaedia of Library and Information Science V . 5 :16-42.

CO NA CyT. (1995)- Indicadores: deadividades dentíficasy tecnológicas México : SEP, CO NACYT. pp 233. 
114 Investigación Bibliotecológica v. 12 N o. 25 julio/ diciembre de 1998

Anexo

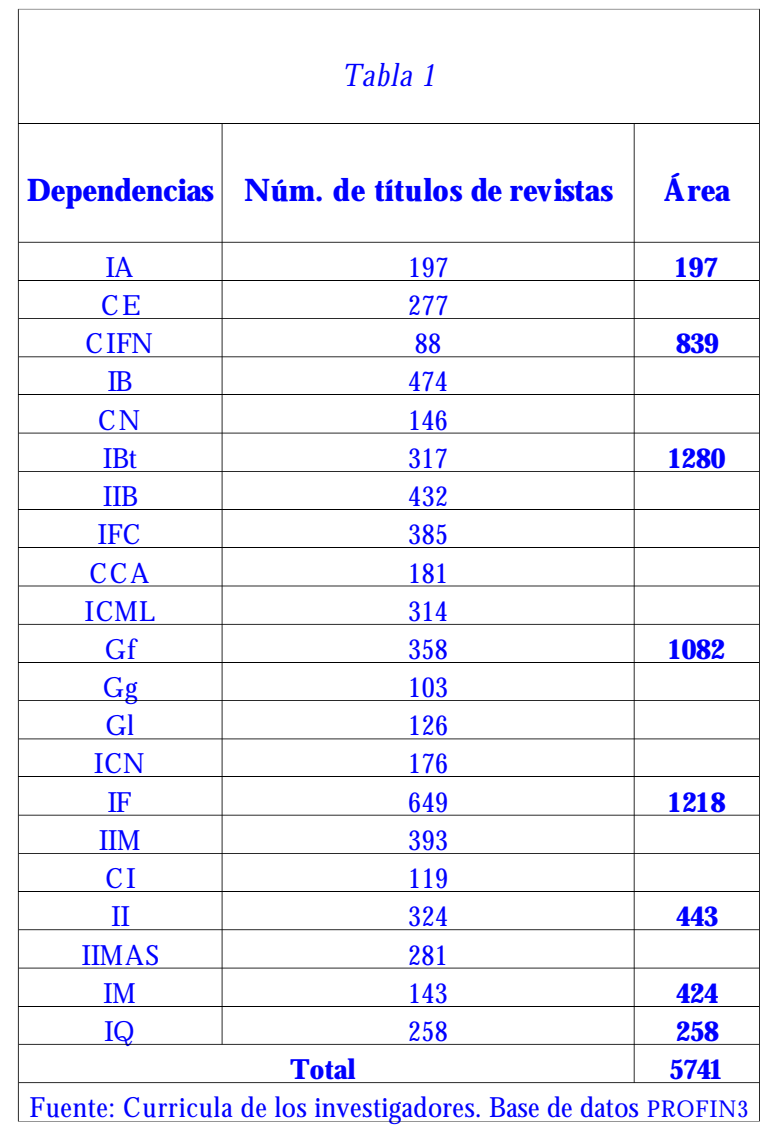

\begin{tabular}{|c|c|c|}
\hline \multicolumn{3}{|c|}{ Tabla2 } \\
\hline \multirow{2}{*}{ Dependencias } & Núm. de revistas con FI & Área \\
\hline IA & 72 & $\mathbf{7 2}$ \\
\hline CE & 103 & \\
\hline CIFN & 51 & $\mathbf{2 7 8}$ \\
\hline IB & 124 & \\
\hline CN & 59 & $\mathbf{6 2 4}$ \\
\hline IBt & 167 & \\
\hline IIB & 195 & \\
\hline
\end{tabular}




\begin{tabular}{|c|c|c|}
\hline \multicolumn{3}{|c|}{$\begin{array}{c}\text { Tabla } 2 \\
\text { (continuación) }\end{array}$} \\
\hline Dependencias & $\mathrm{N}$ úm. de revistas con $\mathrm{FI}$ & Área \\
\hline IFC & 203 & \\
\hline $\mathrm{CCA}$ & 38 & \\
\hline ICML & 73 & \\
\hline Gf & 70 & 206 \\
\hline $\mathrm{Gg}$ & 6 & \\
\hline $\mathrm{Gl}$ & 19 & \\
\hline ICN & 72 & \\
\hline IF & 227 & 468 \\
\hline IIM & 169 & \\
\hline $\mathrm{CI}$ & 45 & \\
\hline II & 63 & 108 \\
\hline IIMAS & 109 & \\
\hline IM & 56 & 165 \\
\hline IQ & 119 & 119 \\
\hline \multicolumn{2}{|r|}{ Total } & 2040 \\
\hline \multicolumn{2}{|r|}{ Total global } & 5741 \\
\hline
\end{tabular}

\begin{tabular}{|c|c|c|}
\hline \multicolumn{3}{|c|}{ Tabla 3 } \\
\hline \multirow{2}{*}{ Dependencias } & N úm. de revistas sin FI & Área \\
\hline IA & 125 & $\mathbf{1 2 5}$ \\
\hline CE & 174 & \\
\hline CIFN & 37 & $\mathbf{5 6 1}$ \\
\hline IB & 350 & \\
\hline CN & 87 & $\mathbf{6 5 6}$ \\
\hline IBt & 150 & \\
\hline IIB & 237 & \\
\hline IFC & 182 & \\
\hline CCA & 143 & $\mathbf{8 7 6}$ \\
\hline ICML & 241 & \\
\hline Gf & 288 & \\
\hline Gg & 97 & \\
\hline Gl & 107 & \\
\hline IC N & 104 & \\
\hline
\end{tabular}


116 Investigación Bibliotecológica v. 12 N o. 25 julio/ diciembre de 1998

\begin{tabular}{|c|c|c|}
\hline \multicolumn{3}{|c|}{$\begin{array}{c}\text { Tabla } 3 \\
\text { (continuacón) }\end{array}$} \\
\hline Dependencias & Núm. de revistas sin FI & Área \\
\hline IF & 422 & 750 \\
\hline IIM & 224 & \\
\hline CI & 74 & \\
\hline II & 261 & 335 \\
\hline IIMAS & 172 & \\
\hline IM & 87 & 259 \\
\hline IQ & 139 & 139 \\
\hline \multicolumn{2}{|r|}{ Total } & 3701 \\
\hline \multicolumn{2}{|c|}{ Total global } & 5741 \\
\hline
\end{tabular}

\begin{tabular}{|c|c|c|}
\hline \multicolumn{3}{|c|}{ Tabla 4} \\
\hline Dependencias & $\begin{array}{c}\text { Número de docu- } \\
\text { mentos por } \\
\text { Dependencia }\end{array}$ & Área \\
\hline IA & 2598 & 2598 \\
\hline CE & 1223 & \\
\hline CIFN & 629 & 5387 \\
\hline IB & 3535 & \\
\hline $\mathrm{CN}$ & 962 & \\
\hline IBt & 1738 & \\
\hline IIB & 1684 & 6529 \\
\hline IFC & 2145 & \\
\hline $\mathrm{CCA}$ & 937 & \\
\hline ICML & 1901 & \\
\hline Gf & 2427 & 7083 \\
\hline $\mathrm{Gg}$ & 910 & \\
\hline $\mathrm{Gl}$ & 908 & \\
\hline $\mathrm{ICN}$ & 901 & \\
\hline IF & 5589 & 8669 \\
\hline IIM & 2179 & \\
\hline $\mathrm{CI}$ & 801 & \\
\hline II & 3617 & 4418 \\
\hline IIMAS & 1462 & \\
\hline IM & 787 & 2249 \\
\hline IQ & 2592 & 2592 \\
\hline \multicolumn{2}{|c|}{ Total } & 39525 \\
\hline
\end{tabular}


Indicadores científicos: evaluaciones negativas proposiciones positivas 117

\begin{tabular}{|c|c|c|c|c|c|c|c|c|c|}
\hline \multicolumn{10}{|c|}{$\begin{array}{c}\text { Tabla } 5 \\
\text { Producción de los Investigadores del SIC por años de publicación }\end{array}$} \\
\hline \multirow[t]{2}{*}{ Áreas } & \multirow{2}{*}{$\begin{array}{l}\text { Depen- } \\
\text { dencias }\end{array}$} & \multicolumn{8}{|c|}{ N úmero de artículos } \\
\hline & & 1940-1949 & 1950-1959 & 1960-1969 & 1970-1979 & 1980-1989 & 1990-1994 & O bservaciones & TOTAL \\
\hline Astronomía & IA & & 6 & 44 & 235 & 994 & 520 & & 1799 \\
\hline \multirow{3}{*}{ Biología } & $\mathrm{CE}$ & & & 18 & 73 & 368 & 343 & & 802 \\
\hline & CIFN & & 1 & 18 & 51 & 110 & 84 & & 264 \\
\hline & IB & 14 & 37 & 116 & 538 & 1250 & 493 & 4 en 1938 & 2452 \\
\hline \multirow{4}{*}{ Biomédica } & $\mathbf{C N}$ & & 1 & 62 & 166 & 240 & 81 & & 550 \\
\hline & IBt & & & & 99 & 576 & 531 & $5 \sin$ año & 1211 \\
\hline & IIB & & 74 & 114 & 220 & 549 & 284 & 3 en 1995 & 1244 \\
\hline & IFC & & 6 & 109 & 304 & 731 & 534 & $3 \sin$ año & 1687 \\
\hline \multirow{5}{*}{$\begin{array}{l}\text { Ciencias de } \\
\text { la Tierra }\end{array}$} & CCA & 1 & 13 & 56 & 128 & 269 & 129 & & 596 \\
\hline & CCMyL & & 22 & 59 & 181 & 505 & 326 & & 1093 \\
\hline & IGf & 2 & 8 & 82 & 239 & 855 & 416 & & 1602 \\
\hline & IGg & & 1 & 24 & 92 & 135 & 80 & & 332 \\
\hline & IGl & & 9 & 17 & 33 & 171 & 109 & & 339 \\
\hline \multirow{3}{*}{ Física } & ICN & & & 10 & 79 & 320 & 268 & & 677 \\
\hline & IF & 3 & 52 & 201 & 640 & 1994 & 1480 & & 4370 \\
\hline & IIM & & & 17 & 147 & 530 & 526 & $7 \sin$ año & 1227 \\
\hline \multirow{2}{*}{$\begin{array}{l}\text { Ingenieía } \\
\text { y T. }\end{array}$} & CI & & & & 35 & 150 & 109 & $8 \sin$ año & 302 \\
\hline & II & & 25 & 111 & 184 & 452 & 251 & 1 en 1995 & 1024 \\
\hline \multirow[t]{2}{*}{ Matemáticas } & IIMAS & & & 17 & 162 & 260 & 169 & & 608 \\
\hline & IM & 7 & 17 & 59 & 89 & 220 & 149 & & 541 \\
\hline Q uímica & IQ & 2 & 23 & 189 & 442 & 1246 & 533 & $4 \sin$ año & 2439 \\
\hline \multicolumn{2}{|c|}{ Total } & 29 & 295 & 1323 & 4137 & 11925 & 7415 & 35 & 25159 \\
\hline & & : curn & a históri & le los Inve & stigadores. I & Base de dat & RO D FIN & (L2) & \\
\hline
\end{tabular}


118 Investigación Bibliotecológica V. 12 N o. 25 julio/ diciembre de 1998

\begin{tabular}{|c|c|c|c|c|c|c|c|}
\hline \multicolumn{8}{|c|}{$\begin{array}{c}\text { Tabla } 6 \\
\text { Porcentaje de citas esperadas por dependencia }\end{array}$} \\
\hline Áreas & Dependencias & $\begin{array}{l}\text { Núm. de citas } \\
\text { por } D \text { ep. }\end{array}$ & $\begin{array}{l}\text { Núm. de citas } \\
\text { por área }\end{array}$ & $\begin{array}{l}\text { Núm. de } \\
\text { artículos por } \\
\text { Dep. }\end{array}$ & $\begin{array}{l}\text { Núm. de } \\
\text { artículos por } \\
\text { área. }\end{array}$ & $\begin{array}{l}\text { Impacto de la } \\
\text { Dep. } \\
\text { \#citas / \# art. }\end{array}$ & $\begin{array}{l}\text { Impacto del } \\
\text { área } \\
\text { \#citas / \# art. }\end{array}$ \\
\hline Astronomía & IA & 15984 & 15984 & 1799 & 1799 & 8.8 & 8.8 \\
\hline \multirow{3}{*}{ Biología } & CE & 3803 & & 802 & & 4.74 & \\
\hline & CIFN & 4314 & 10609 & 264 & 3518 & 16.34 & 3 \\
\hline & IB & 2492 & & 2452 & & 1 & \\
\hline \multirow{4}{*}{ Biomédica } & $\mathrm{CN}$ & 4974 & & 550 & & 9.04 & \\
\hline & IBt & 26062 & 58985 & 1211 & 4692 & 21.52 & 12.5 \\
\hline & IIB & 9490 & & 1244 & & 7.62 & \\
\hline & IFC & 18459 & & 1687 & & 10.94 & \\
\hline \multirow{5}{*}{ C. de la Tierra } & CCA & 864 & & 596 & & 1.44 & \\
\hline & CCMyL & 2191 & & 1093 & & 2 & \\
\hline & Gf & 4009 & 9451 & 1602 & 3962 & 2.50 & 2.3 \\
\hline & Gq & 46 & & 332 & & 0.13 & \\
\hline & Gl & 2341 & & 339 & & 6.90 & \\
\hline \multirow{3}{*}{ Física } & ICN & 4155 & & 677 & & 6.13 & \\
\hline & IF & 22301 & 30229 & 4370 & 6274 & 5.10 & 4.8 \\
\hline & IIM & 3773 & & 1227 & & 3.07 & \\
\hline \multirow[t]{2}{*}{ Ingeniería y $\mathrm{T}$. } & CI & 498 & 2842 & 302 & 1326 & 1.64 & 2.14 \\
\hline & II & 2344 & & 1024 & & 2.28 & \\
\hline \multirow[t]{2}{*}{ Matemáticas } & IIMAS & 1521 & 2341 & 608 & 1149 & 2.50 & 2 \\
\hline & IM & 820 & & 541 & & 1.51 & \\
\hline Química & IQ & 9477 & 9477 & 2439 & 2439 & 3.88 & 3.8 \\
\hline TOTAL & & 139918 & & 25159 & & & \\
\hline
\end{tabular}

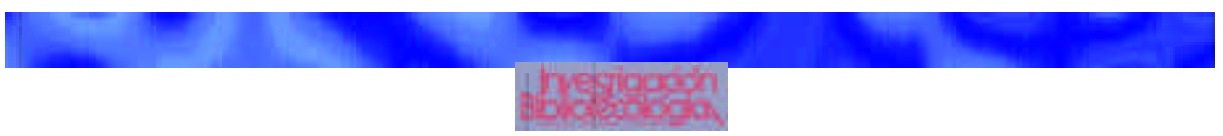

